Type of the Paper (Article)

\title{
Oceanic Response Based on the Rectified Data during Three Typhoons in the northern South China Sea
}

\author{
Daoxun $\mathrm{Ke}^{1,2}$, Han Zhang ${ }^{2,3,{ }^{*}}$, Youmin Tang1, 2, 4, ${ }^{*}$, Juncheng $\mathrm{Zuo}^{5}$, Dongfeng $\mathrm{Xu}^{2}$, Chenghao \\ Yang', Zhixiong $\mathrm{Yao}^{2}$, Zheqi Shen ${ }^{1}$, Di Tian ${ }^{2}$ \\ ${ }^{1}$ College of Oceanography, Hohai University, Nanjing, China \\ 2 State Key Laboratory of Satellite Ocean Environment Dynamics, Second Institute of Oceanography, \\ Ministry of Natural Resources, Hangzhou, China \\ ${ }^{3}$ Southern Marine Science and Engineering Guangdong Laboratory (Zhuhai), Zhuhai, China \\ ${ }^{4}$ Environmental Science and Engineering, University of Northern British Columbia, Prince George, \\ British Columbia, Canada \\ ${ }^{5}$ College of Marine Sciences, Shanghai Ocean University, Shanghai, China \\ *Correspondence: zhanghan@sio.org.cn; ytang@sio.org.cn
}

Received: date; Accepted: date; Published: date

\begin{abstract}
Three typhoons (Rammasun, Kalmaegi, and Sarika) travelled through the deployed stations in the northern South China Sea from 2014-2016. During the passage of typhoons, strong winds and vigorous currents resulted in horizontal displacement of buoy over $2000 \mathrm{~m}$, vertical displacement of ropes on buoys as much as $200 \mathrm{~m}$. The rectification can correct the warm anomaly to cool anomaly of temperature. These movements lead to biases of raw data, with temperature bias as much as $4^{\circ} \mathrm{C}$, salinity as much as $0.05 \mathrm{psu}$, velocity bias as much as $0.4 \mathrm{~m} / \mathrm{s}$. The crosscheck of current velocity from different instruments shows that the bias of overlapping velocity and correlation coefficient after depth rectification obviously enhances. The observation shows that temperature cools $1.5^{\circ} \mathrm{C}$, and 0.1 psu saltier in maximum, the nearinertial current increases to $0.4 \mathrm{~m} / \mathrm{s}$ in the upper layer. The inertial kinetic energy propagates downward with the upward phase, and the maximum depth can reach over $2000 \mathrm{~m}$.
\end{abstract}

Keywords: rectification; bias; typhoon; kinetic energy

\section{Introduction}

Tropical cyclones (TCs) are non-frontal low-pressure atmospheric systems characterized by intense vertical convection and closed lower-level wind fields. These form develop in certain tropical or subtropical zones; mature TCs (winds reaching $32.7 \mathrm{~m} \mathrm{~s}^{-1}$, CMA typhoon category) generate in the western Pacific Ocean are called typhoons, while those (winds reaching $64 \mathrm{~m} \mathrm{~s}^{-}$ 1, Saffir-Simpson Hurricane Wind Scale) generate in the eastern Pacific and Atlantic Oceans are called hurricanes. TCs are among the most intensive processes in the atmosphere, which 
influence certain locations about $0.5 \mathrm{~d}$ in force stage and about a week or more in relaxed stage [1]. The northwest Pacific Ocean, especially South China Sea is the most active region for TCs generation all over the world.

Observations and model results indicate that TCs cause notable thermal ocean responses, such as sea-surface cooling and decreasing salinity or subsurface warming and increasing salinity [1-10]. An analysis of Argo data from 1996 to 2012 showed that the average surface cooling produced by TCs is $\sim 1.4{ }^{\circ} \mathrm{C}$ along track during $\sim 20 \mathrm{~d}$ in the shallower mixed layer [11]. Generally, the mixing caused by TCs of intensity greater than Category IV leads to warm anomaly extends to the top of thermocline, taking recover time longer than that of surface and additionally generating net ocean heat uptake propagating in deeper layer $[1,12]$. On the other hand, the response of salinity to typhoons has little to do with air-sea flux, but is closely related to precipitation (which decreased salinity, e.g., [13]) and upwelling (which increased it). Ocean salinity variation predominantly associates with TCs intensity ([14]) and the vertical stratification caused by salinity reduced $50 \%$ ocean cooling [15].

The dynamic response of TCs is close to the near-inertial current and energy propagation. TCs remarkably motivate horizontal near-inertial currents and vertical upwelling and downwelling in the relaxed stage [1]. The near-inertial currents in mixed layer drive convergence and divergence in thermocline to generate upwelling and downwelling. The upwelling (downwelling) leads to upper ocean cold (warm) anomaly [1, 3, 8, 16-18]. In addition, upwelling induced by TCs cools the upper ocean [19] and transports abyssal nutrients to the photic layer, facilitating phytoplankton bloom via photosynthesis [20-21]. In turn, abundant phytoplankton provides nutrients to zooplankton, which promotes the development of ecosystem circulation.

It is assumed that the energy propagation in the upper layer hardly dissipates due the mixed layer dispersion that drives the thermocline current. However, Alford et al. [20] deems that near-inertial energy reflects several times in pycnocline and dissipates after several inertial periods. In the other aspect, $\mathrm{Xu}$ et al. [22] believes that typhoon pours energy within the ocean by the form of surface waves dispersion. Plenty of observations [23-28] indicate that nearinertial kinetic energy cross the mixed layer and permeates below the upper layer.

During typhoon, the intense winds and energetic near-inertial waves created by typhoons always disturb observed platforms, resulting in missing data or biases that required rectification for accurate results. In addition, phytoplankton and zooplankton patterns in the wake of TCs (especially the day-night migration of zooplankton) brings the contaminations of data by affecting the echo intensity of acoustic instruments [9, 20-21, 29-30].

Some data rectification schemes are applied for correction in previous study. For instance, horizontal rectification scheme is applied to wipe out horizontal bias induced by the horizontal movement of the measured platforms [31-32]. Vertical rectification scheme is applied to adjust the vertical position of the observed data [8-27]. Tilt rectification scheme is applied for the rectification of the instrument wobbling [33], and correct dynamic draft error [34].

From 2014 to 2016, three typhoons travelled through our observation stations in the northern South China Sea, producing a useful dataset for further study of the influence of such storms on the data quality and the responses of ocean. The structure of this paper is organized as 
follows. Three captured typhoons and observations reviews are depicted in section 2 . The data Biases are quantitatively calculated, and data is rectified in section 3. Oceanic response are exclaimed in section 4 . Finally, the methods of rectification and oceanic response are concluded in section 5 .

\section{Typhoons and Observations}

\subsection{Typhoons}

Three Typhoon Rammasun, Kalmaegi and Sarika crossed over our deployed stations during

2014-2016. The best-track data for these storms from the Joint Typhoon Warning Center

(JTWC, https://metoc.ndbc.noaa.gov/web/guest/jtwc/best_tracks), China Meteorological

Agency (CMA, http://tcdata.tyhpoon.gov.cn/zjljsjj_zlhq.html), and Japan Meteorological

Agency (JMA, http://www.jma.go.jp/jma/jma-eng/jma-center/rsmc-hp-pub-eg/besttrack.html)

is used to depict them in details in Figure 1.

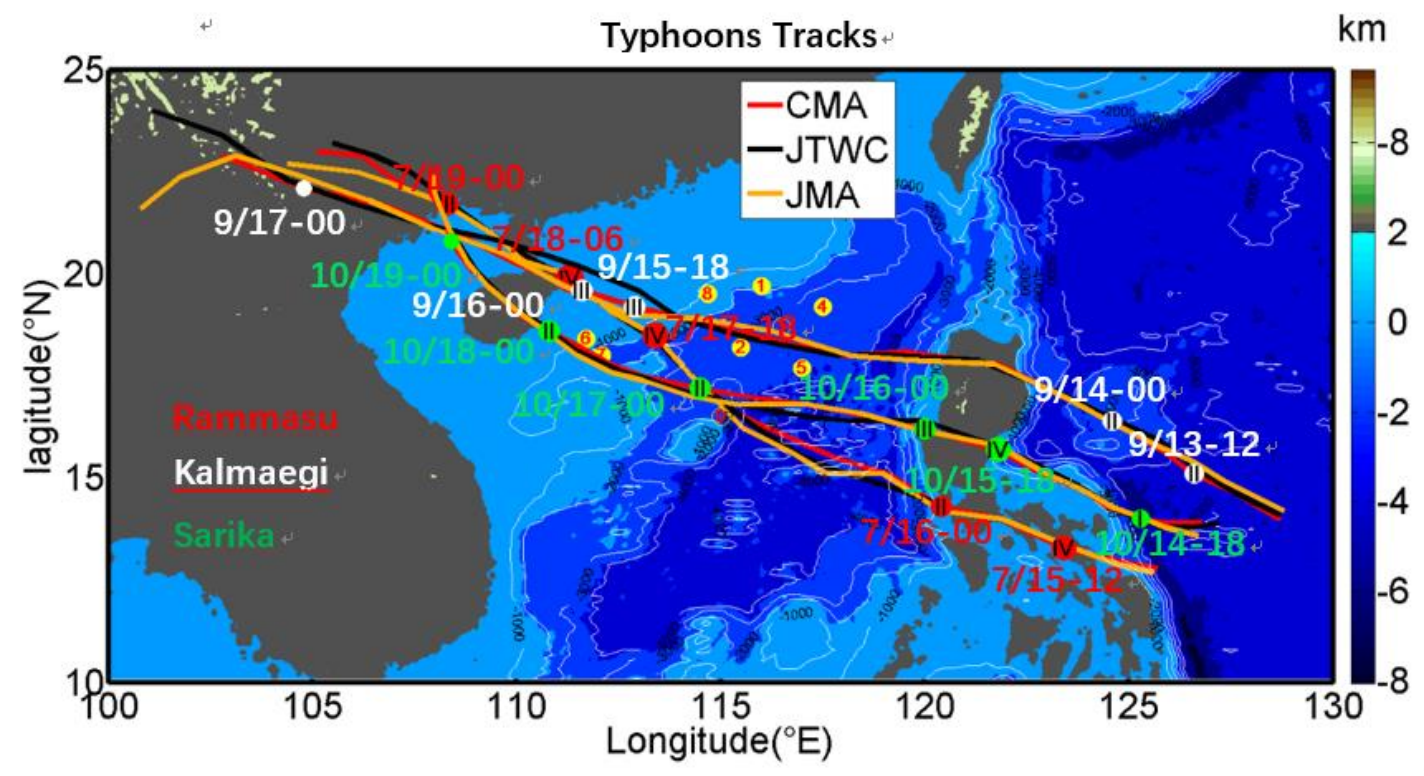

Figure 1. Best tracks of the three typhoons considered in this study: Rammasun (July 2014, red circle) and Kalmaegi (September 2014, white circle), Sarika (October 2016, green circle). Yellow circles with red numbers indicate stations locations, while circles 3, 9 without yellow filling lost extensive data. Circles with Raman numbers are the position of maximum sustained wind speed per day, the size of circles indicate typhoon intensity classified by CMA typhoon category. Color gradients represent surface elevation above or below sea level. It is noted that the time form is month/day-hour. Data draws from the China Meteorological Agency (CMA, 
red), Joint Typhoon Warning Center (JTWC, black), and Japan Meteorological Agency (JMA, brown).

Rammasun is the ninth tropical cyclone of 2014 in the northwestern Pacific. It formed east of Guam and reached typhoon strength on July 14, hitting the northern Philippines at Category IV strength before weakening as it entered the South China Sea on July 15. It quickly restrengthened to Category IV while passing over our stations on July 17 because warm seasurface temperatures supplied energy to intensify it [35]. Then, its maximum sustained wind speed strengthened to $72 \mathrm{~m} / \mathrm{s}$ on 18-Jul-2014 06:00:00 UTC. It eventually reached Category III status before making landfall, causing serious environmental damage and economic losses in southern China.

Kalmaegi is the fifteenth tropical cyclone of 2014 in the northwestern Pacific. It formed near Palau, reaching typhoon strength on September 13 before travelling west-northwest across the northern Philippines. It passed over our stations in the South China Sea on September 15 as a category III typhoon with $42 \mathrm{~m} / \mathrm{s}$ maximum sustained wind speed at 18:00:00. It weakened further before making landfall in China from September 16-17.

Sarika is the twenty-first tropical cyclone of 2016 in the northwestern Pacific. It formed east of the Philippines, reached Category IV with $55 \mathrm{~m} / \mathrm{s}$ maximum sustained wind speed at 18:00:00 before making landfall there on 15 October, then entered the South China Sea on October 15 and passed over our stations at Category II. It eventually made landfall on China at Category I on October 18.

\subsection{Observations}

The stations consist buoys and moorings. Station 5 and 6 are moorings, Stations $1-4$ and 7-9 are both consisted by a buoy and a mooring. As shown in Figure 2, buoys are fitted with traditional meteorological instruments, AIRMAR-200WX meteorological instruments, wave gauges and GPS (Global Position System) units, both of them with 1-hr time interval; the CTDs (Conductivity-Temperature-Depths) with 2-min time interval and 20-40 m depth interval; the ADCPs (Acoustic Doppler Current Profilers) with 3-min time interval. The moorings included ADCPs with 3-min time interval in the upper layer, 15-min time interval in the middle layer; the Seaguard current meters with 10-min time interval; the CTDs with the 3-min time interval. For ease of comprehension and analysis, we divided the observed depths into three layers based on the buoy- and mooring-mounted ADCPs. Layer 1, the observed water depth of the down-looking $150 \mathrm{kHz}$ ADCP on buoy (surface, 0-200 m); Layer 2, the observed water depth of the up-looking $300 \mathrm{kHz}$ ADCP on mooring (subsurface, 200-300 m); Layer 3, the observed water depth of the down-looking $75 \mathrm{kHz}$ ADCP on mooring (middle layer, 300-900 m). 


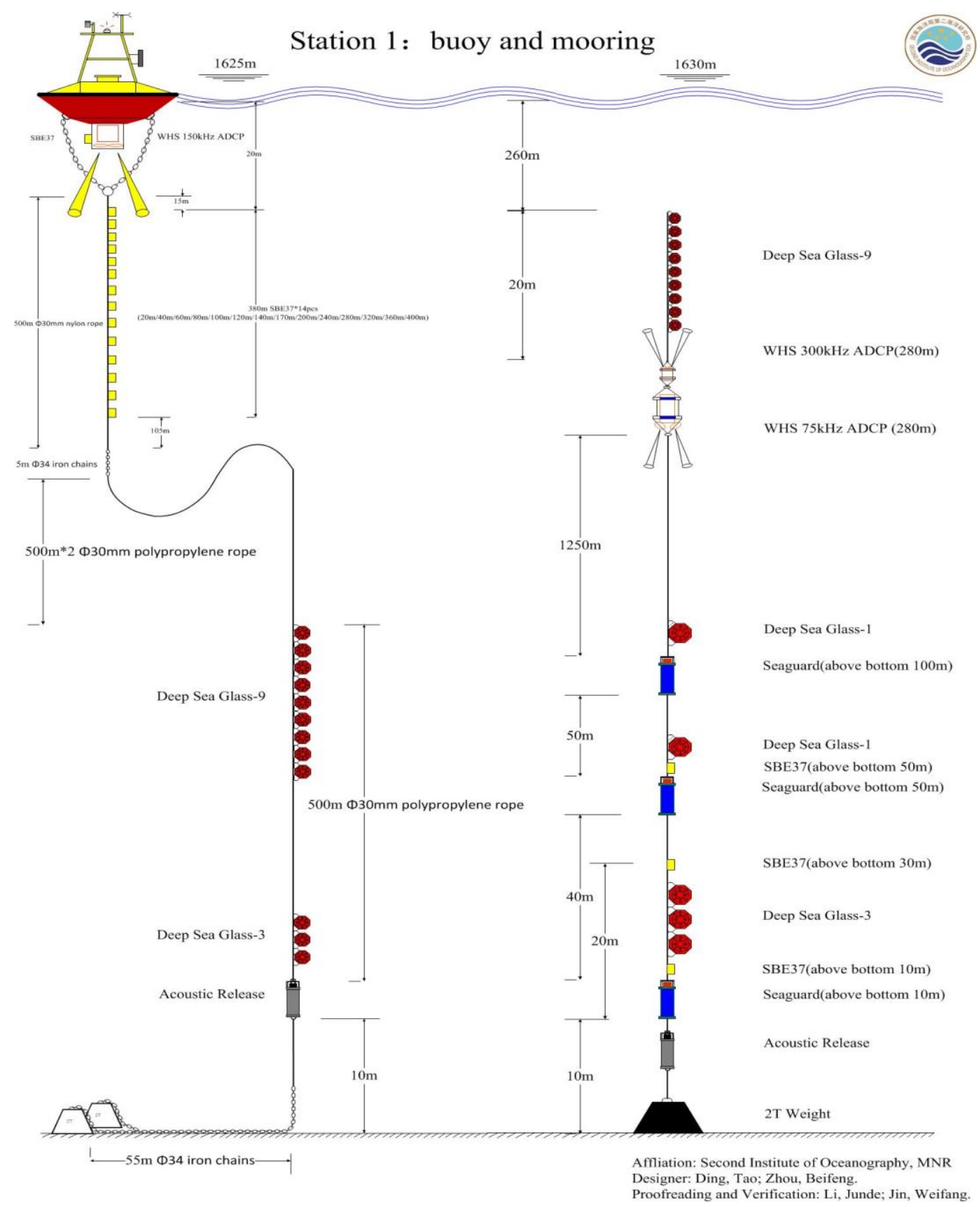

Figure 2. Schematic diagram of Station 1, general representative of other stations used in this study.

\section{Bias Calculation and Rectification of Data}

As shown in Figure 3, strong wind and currents lead to spatial movements and tilt of instruments. The biases includes horizontal displacement, vertical displacement and the tilt angle $\theta$ (the angle of oriented and vertical line). In general, the instruments of buoys move upwards, while moorings move downwards after the passing of typhoon. 
In this section, the bias of the CTDs and ADCPs data are dividedly analyzed, and then corresponding rectification is conducted to data.

(a) Buoy

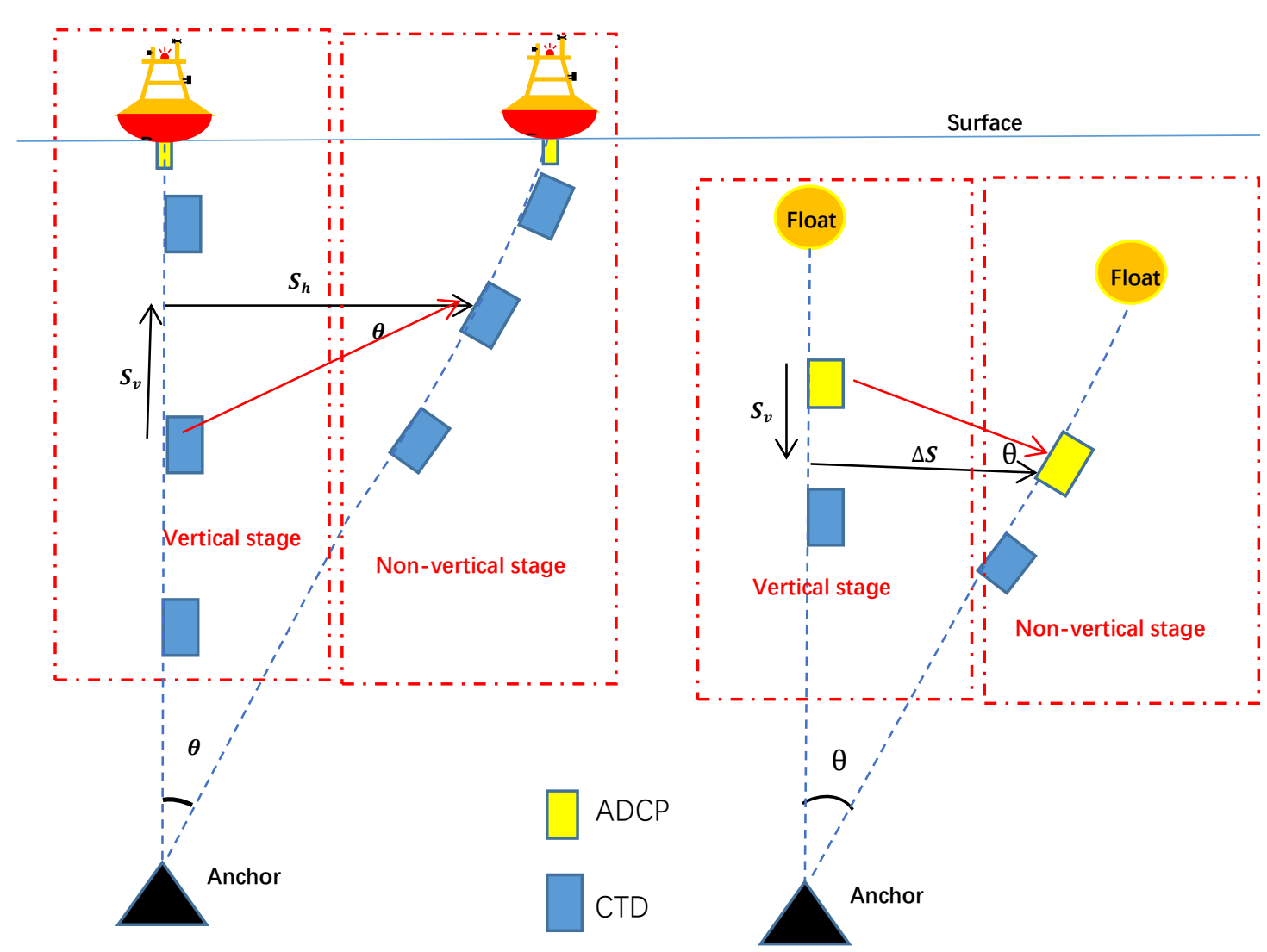

Figure 3. Schematic diagrams of instruments' displacements on (a) buoy and (b) mooring. Horizontal shift $\Delta S$, horizontal displacement $S_{h}$, vertical displacement $S_{v}$. Red arrow notes the displacement of the instrument.

\subsection{CTDs Data}

(1) Bias of the CTD Ropes

Influenced by strong winds and currents, ropes tethered with CTDs vibrated horizontally and vertically. The horizontal shift of a CTD can be calculated using the form:

$$
\Delta S(t, i)=\left\{\begin{array}{c}
\sqrt{D_{m}(i)^{2}-D(t, i)^{2}}, i=1 \\
\sqrt{(\Delta D(i))_{m}{ }^{2}-\Delta D(t, i)^{2}}, i=2, \ldots, n
\end{array}\right.
$$

Where $t$ is time, $i$ is the sequence of CTD from shallower to deeper ocean, $n$ is the number of CTDs at the ropes. $\Delta S(t, i)$ is the horizontal shift, $D(t, i)$ is observed depth of CTD $i$ at time $t$, $D_{m}(i)$ is observed maximum depth of CTD $i .(\Delta D(i))_{m}$ is maximum observed depth interval of CTD $i$. It is noted that $\Delta D(t, i)=D(t, i)-D(t, i-1),(\Delta D(i))_{m}=(D(i)-D(i-1))_{m}$ when $i \geq 2$, 
the subscript notes maximum of depth interval. The horizontal displacement $S_{h}(t, i)$ can get approximately through buoy displacement $S_{b}$ minus $\Delta S$ :

$$
\begin{gathered}
S_{h}(t, i)=\left|S_{b}(t)-\sum_{i=1}^{n} \Delta S_{h}(t, i)\right| \\
S_{b}=\sqrt{x^{2}+y^{2}} \\
x=\frac{2 \pi r \cos (\overline{\text { lat }})\left(\text { lon }- \text { lon }_{b}\right)}{360} \\
y=\frac{2 \pi r\left(\text { lat }^{2} \text { lat }_{b}\right)}{360} \\
\operatorname{lon}_{b}=\frac{\text { lon }_{m}+\text { lon }_{m i}}{2} \\
\text { lat }_{b}=\frac{\text { lat }_{m}+\text { lat }_{m i}}{2}
\end{gathered}
$$

where $x$ is the zonal displacement of buoy to the anchor position $\left(\operatorname{lon}_{b}\right.$, lat $\left._{b}\right), y$ is the meridional displacement of buoy to the anchor position. $r=6371 \mathrm{~km}$ is the radius of earth, $\overline{l a t}$ $\left({ }^{\circ}\right)$ is the average of adjacent latitudes. Ion $\left(^{\circ}\right)$ and $\operatorname{lat}\left(^{\circ}\right)$ is observed longitude and latitude of GPS, respectively. The vertical displacement $S_{v}(\mathrm{t}, \mathrm{i})$ of ropes can be expressed as

$$
S_{v}(\mathrm{t}, \mathrm{i})=D_{m}(i)-D(t, i)
$$

The tilt angle

$\theta=S_{v} / S_{v}$

As shown in Figure 4, horizontal shift $\Delta S_{h}$ increases with the increasing depth, its maximum can reach $400 \mathrm{~m}$ in thermocline. The horizontal displacement decreases with the increasing depth, its maximum can reach $2000 \mathrm{~m}$ at the surface. The vertical displacement increases with the increasing depth, its maximum can reach $200 \mathrm{~m}$ in thermocline. The tilt angle increases with increasing depth, it maximum can reach $80^{\circ}$ in thermocline. In a word, the displacements and tilt are apparently increased after the passing of Kalmaegi. 
(a) $T_{n}\left({ }^{\circ} \mathrm{C}\right), \mathrm{B} 2$

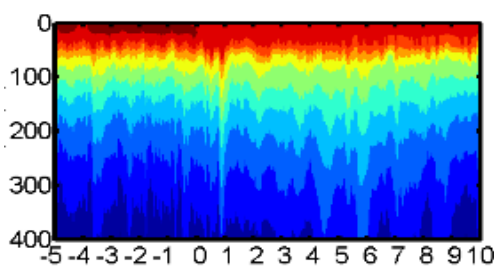

(c) $T_{n}\left({ }^{\circ} \mathrm{C}\right), \mathrm{B} 4$

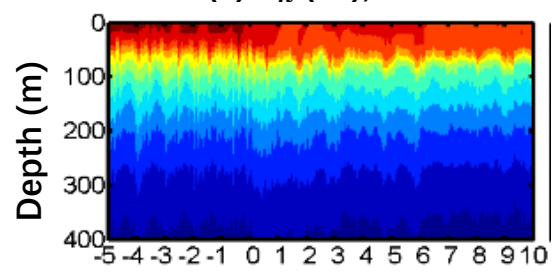

(e) $T_{n}\left({ }^{\circ} \mathrm{C}\right), \mathrm{B} 5$

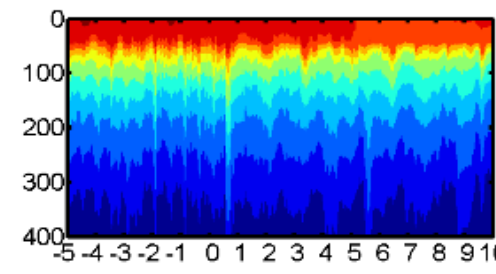

(b) $T_{d}\left({ }^{\circ} \mathrm{C}\right), \mathrm{B} 2$

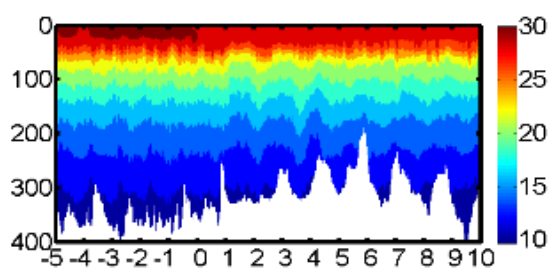

(d) $T_{d}\left({ }^{\circ} \mathrm{C}\right), \mathrm{B} 4$

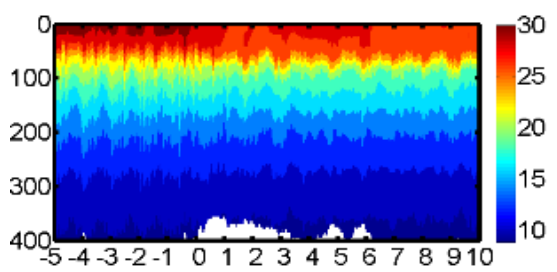

(f) $T_{d}\left({ }^{\circ} \mathrm{C}\right), \mathrm{B} 5$

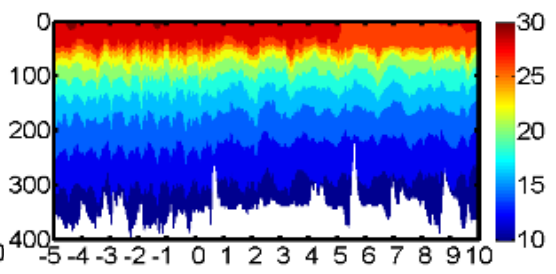

Time (d) (g) $S_{n}$ (psu), B2

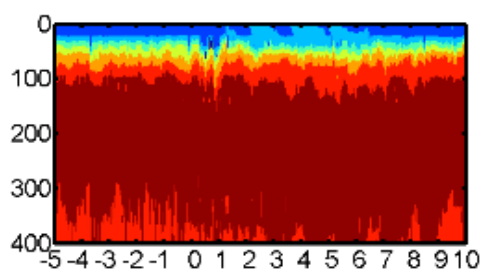

(i) $S_{n}(\mathrm{psu}), \mathrm{B} 4$

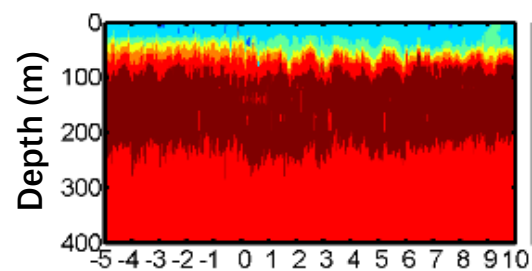

(k) $S_{n}$ (psu), B5

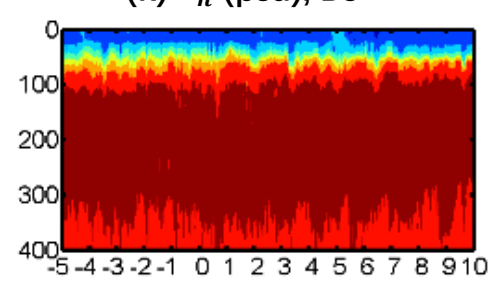

(h) $S_{d}$ (psu), B2

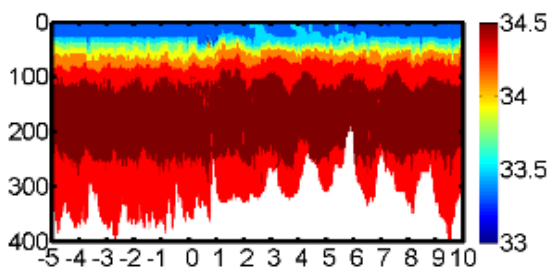

(j) $S_{d}$ (psu), B4

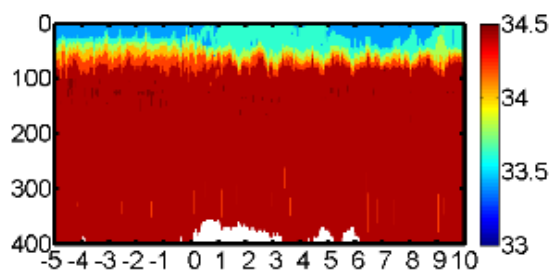

(I) $S_{d}$ (psu), B5

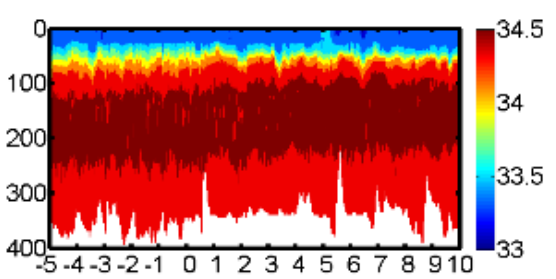

Time (d) 
(i) $\Delta S_{h}(\mathrm{~m})$, B5

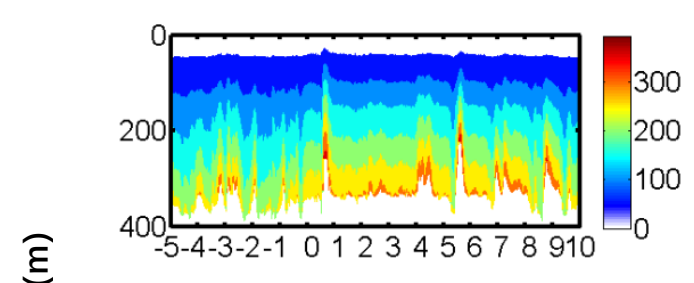

(k) $S_{v}(\mathrm{~m})$, B5

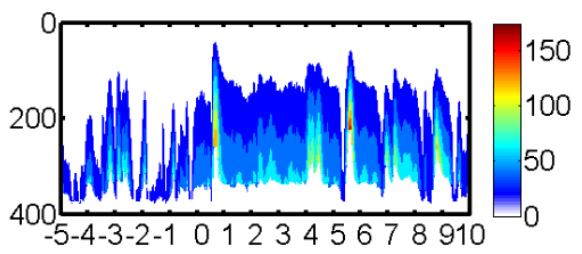

(j) $S_{h}(\mathrm{~m})$, B5

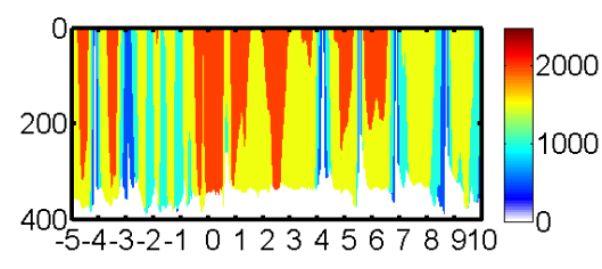

(I) $\theta\left({ }^{\circ}\right)$, B5

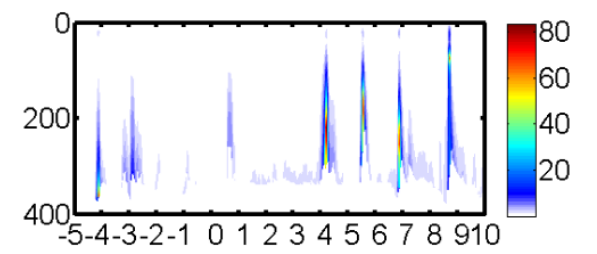

Time (d)

Figure 4. Horizontal shift $\Delta S_{h}$, horizontal displacement $S_{h}$ and vertical displacement $S_{v}$, tilt $\theta$ of CTDs ropes on Buoys 2, 4, 5 (B2, B4, B5). The numbers on the abscissa noted the days before (negative) and after (positive) typhoon Kalmaegi, while 0 noted the day (9/15) Kalmaegi passing stations.

\section{(2) Depth Rectification}

The tilt of CTD is indifferent to its recording data, and the horizontal rectification cannot be carried out due to the vertical deployment of CTD. Therefore, the temperature and salinity of CTD is set off depth rectification. Note that the data before depth rectification corresponds to data of nominal depth. As shown in Figure 5, the isolines of the temperature before depth rectification $T_{n}$ move downwards at 200-300 m after passage of typhoon, while isolines of temperature after depth rectification $T_{d}$ are adjusted to oscillating on the equilibrium position. The halocline of salinity before depth rectification $S_{n}$ is at the range of 100-400 m, while halocline of salinity after depth rectification $S_{d}$ is at the range of $100-200 \mathrm{~m}$. The $T_{d}\left(S_{d}\right)$ is missing in thermocline due to the upwards movement of CTDs ropes. 
(a) $\Delta S_{h}(\mathrm{~m})$, B2

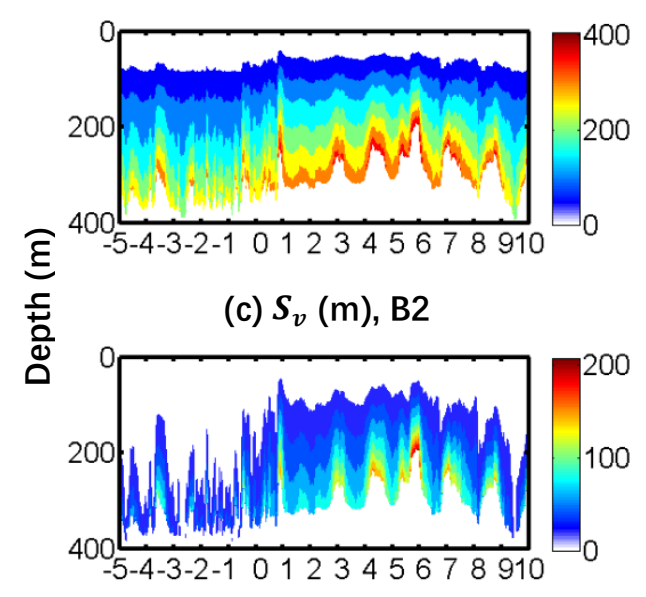

(b) $S_{h}(\mathrm{~m})$, B2

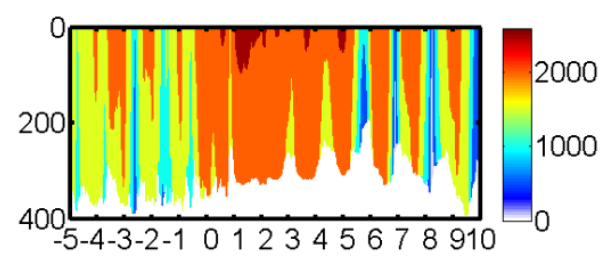

(d) $\theta\left({ }^{\circ}\right), \mathrm{B} 2$

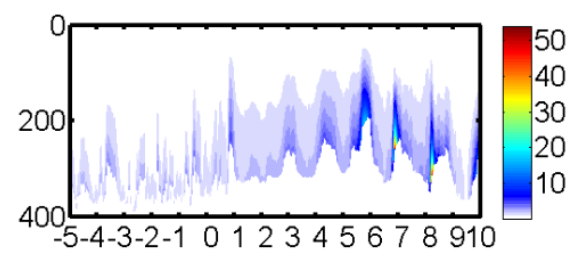

Time (d)

(e) $\Delta S_{h}(\mathrm{~m})$, B4

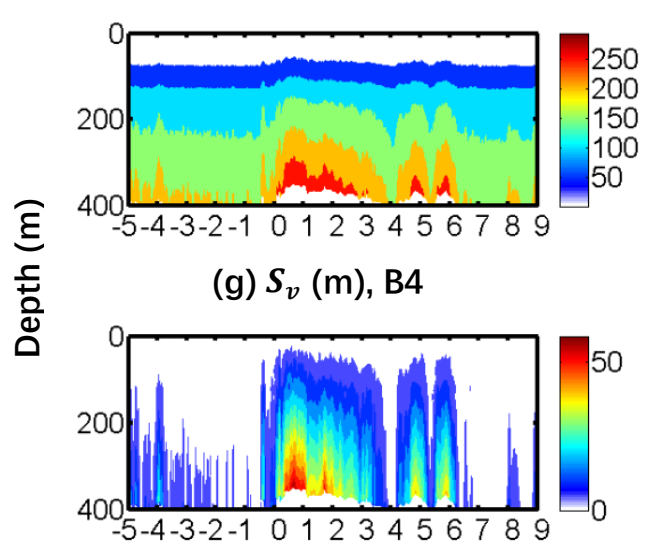

(f) $S_{h}(\mathrm{~m})$, B4

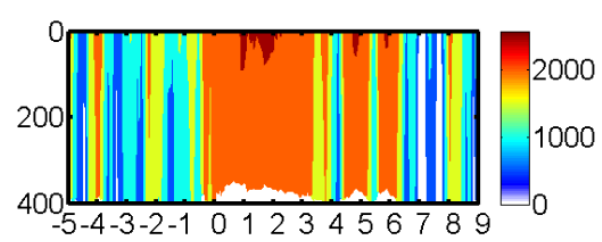

(h) $\theta\left({ }^{\circ}\right), B 4$

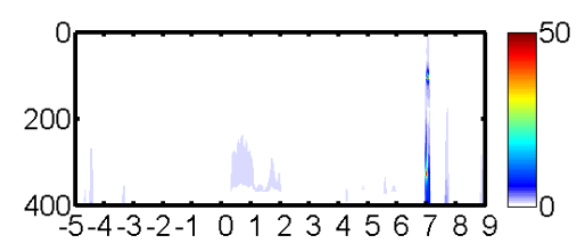

Time (d)

Figure 5. Temperature before depth rectification $T_{n}$ and temperature after depth rectification $T_{d}$, salinity before depth rectification $S_{n}$ and salinity after depth rectification $S_{n}$ on Buoy2, 4, 5 (B2, B4, B5). It's noted that data before depth rectification corresponds data of nominal depth. Numbers on abscissa note time before (negative) and after (positive) Kalmaegi passing.

As shown in Figure 6, it seems unpractical that the temperature anomaly before depth rectification $\Delta T_{n}$ presents warm anomaly in thermocline after passing of typhoon, while the temperature anomaly after depth rectification $\Delta T_{d}$ presents cold anomaly. The salinity anomaly before depth rectification $\Delta S_{n}$ is obvious at the depth beyond $200 \mathrm{~m}$, while the salinity anomaly after depth rectification $\Delta \boldsymbol{S}_{\boldsymbol{d}}$ is obvious at the depth beyond $100 \mathrm{~m}$. The depth rectification bias (DRB) is defined as data after depth rectification minus data of nominal depth, so the DRB of temperature (DRBT) and DRB of salinity (DRBS) can be expressed as $T_{d}-T_{n}$ and $S_{d}-S_{n}$, respectively. The proposed DRB is used to estimate the importance of depth rectification, and 
the depth rectification is more important when DRB is larger. The DRBT decreases notably to $0.4^{\circ} \mathrm{C}$ in the thermocline, while DRBS increases notably to $0.02 \mathrm{psu}$ in the mixed layer in awake of typhoon.

\subsection{ADCP Data}

\subsubsection{Horizontal Displacement of Buoys}

As shown in Figure 7, the deployed buoys move surrounding the fixed points with the radii over $2000 \mathrm{~m}$. The anchor, as the fixed point of Buoy 1 may move on the sea bottom. The movement of moored buoys (Buoys 1, 2, 4, 5) forms a near-circular track away from the anchor, and shift buoy (Buoy 3) forms a near-inertial motion, of which radius decreased with the latitude, and refracted on the critical latitude $\left(\sim 19.5^{\circ}\right)$.

(a) Track (m), B1

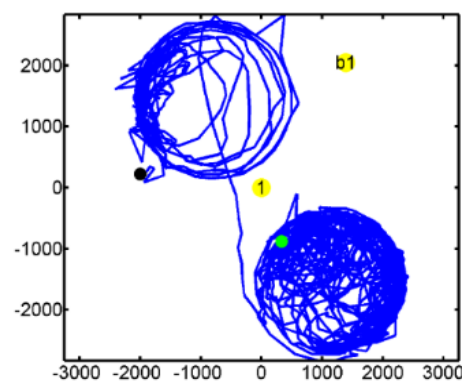

(c) Track (m), B4

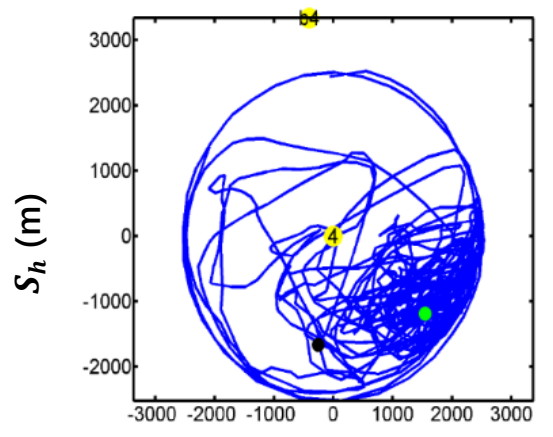

(b) Track (m), B2

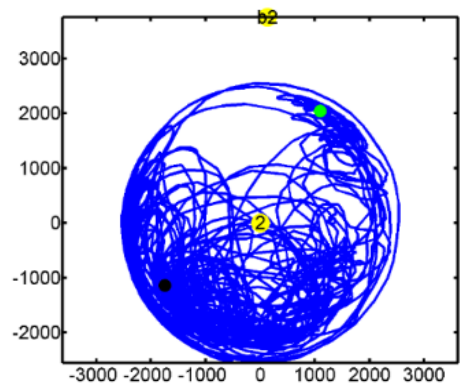

(d) Track (m), B5

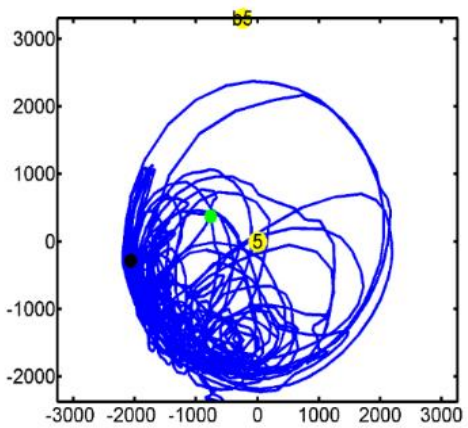

(e) Track (m), B3

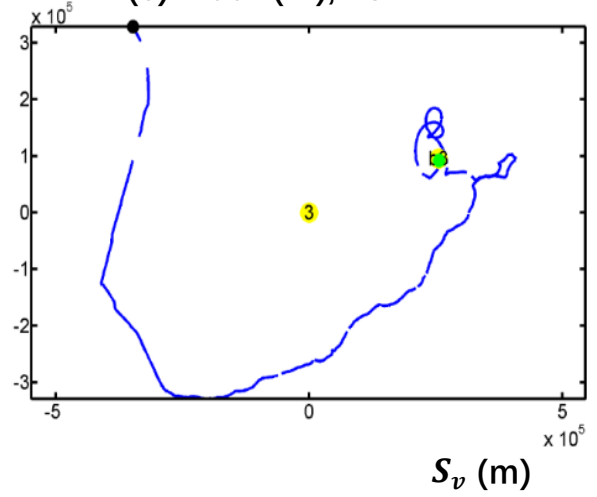


Figure 7. Tracks of Buoys 1-5(B1-B5). Horizontal displacement $S_{h}$ and vertical displacement $S_{v}$. Yellow filling circles with b1-b5 mean nominal deployed positions of Buoys 1-5, yellow filling circles with 1-5 mean anchor position. Green and black dots indicate the original and terminative positions of the buoys, respectively.

\subsubsection{Horizontal Rectification}

The movement of buoys bring bias on the data of the fixed ADCP, so it is necessary to wipe out the errors using horizontal rectification. The horizontal velocity vectors are given through the following formula:

$$
\begin{gathered}
u_{h}=\frac{2 \pi r \cos (\overline{\text { lat }}) \Delta \operatorname{lon} / 360}{\Delta t} \\
v_{h}=\frac{2 \pi r \Delta l a t / 360}{\Delta t}
\end{gathered}
$$

Where $\Delta$ lon $\left(^{\circ}\right)$ and $\Delta$ lat $\left(^{\circ}\right)$ are the backward difference of longitude and latitude,

respectively. $\Delta t=3600 \mathrm{~s}$ is the sampled time interval. $u_{h}$ and $v_{h}$ is zonal and meridional horizontal velocity of buoys, respectively. Note that the ADCPs fixed in buoy had the same horizontal velocity of buoys. As shown in Figure 8, the horizontal velocity of fixed buoys with maximum velocity of $\sim 0.2 \mathrm{~m} / \mathrm{s}$ prominently increased after the typhoon passage, while 
shift buoy (Buoy 3) with $\sim 2 \mathrm{~m} / \mathrm{s}$ maximum velocity magnitude reflects the surface velocity.

(a) $u_{h}(\mathrm{~m} / \mathrm{s}), \mathrm{B} 1$

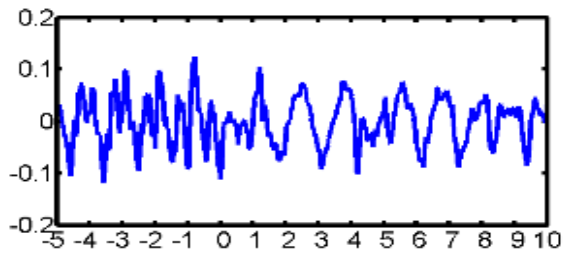

(c) $u_{h}(\mathrm{~m} / \mathrm{s}), \mathrm{B} 2$

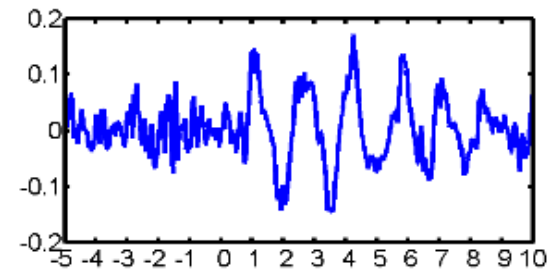

(i) $u_{h}(\mathrm{~m} / \mathrm{s}), \mathrm{B} 3$

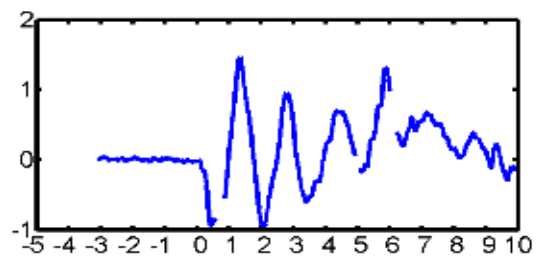

(e) $u_{h}(\mathrm{~m} / \mathrm{s}), \mathrm{B} 4$

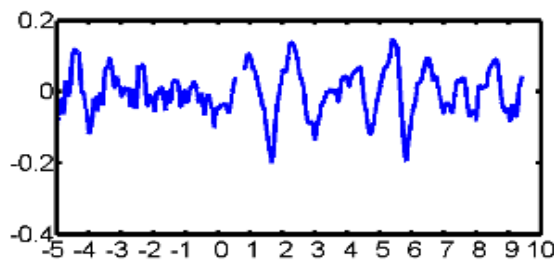

(g) $u_{h}(\mathrm{~m} / \mathrm{s}), \mathrm{B} 5$

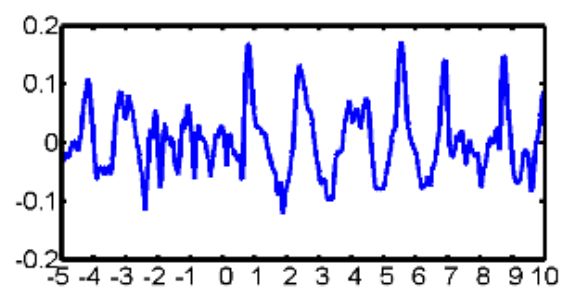

(b) $v_{h}(\mathrm{~m} / \mathrm{s}), \mathrm{B} 1$

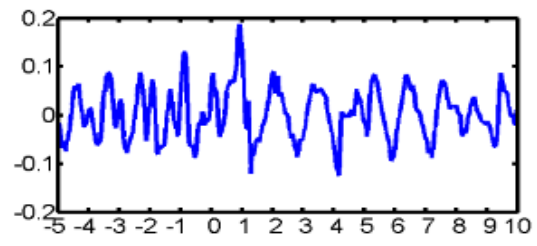

(d) $v_{h}(\mathrm{~m} / \mathrm{s}), \mathrm{B} 2$

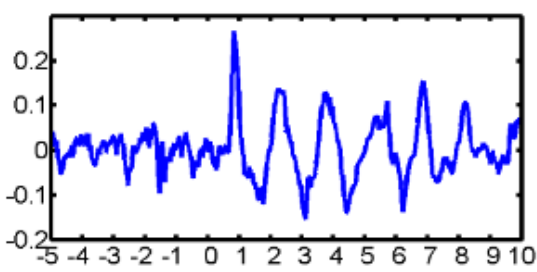

(j) $v_{h}(\mathrm{~m} / \mathrm{s}), \mathrm{B} 3$

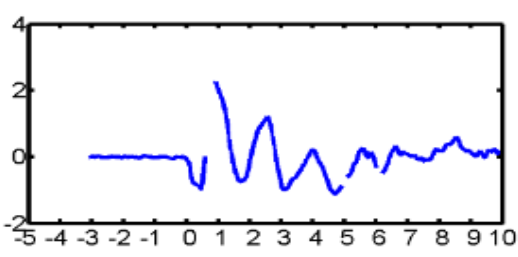

(f) $v_{h}(\mathrm{~m} / \mathrm{s}), \mathrm{B} 4$

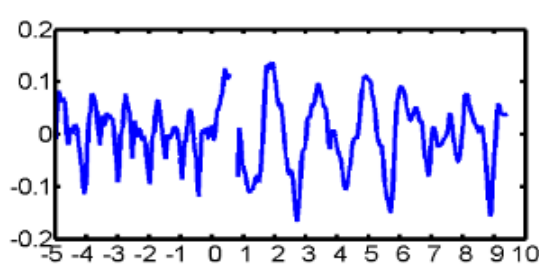

(h) $v_{h}(\mathrm{~m} / \mathrm{s}), \mathrm{B} 5$

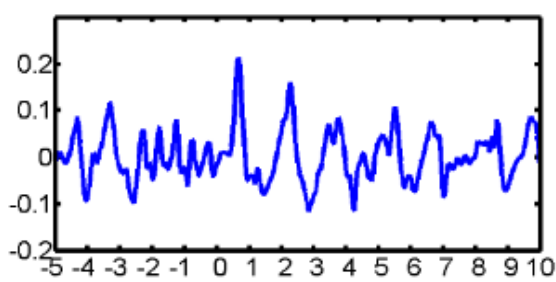

Time (d)

Figure 8. Zonal horizontal velocity $u_{h}$ and meridional horizontal velocity $v_{h}$ of Buoys 1-5 (B1B5). Abscissa represented days before (negative) and after (positive) Kalmaegi passing.

The absolute velocity equals to the relative velocity (observed velocity) plus the transport velocity (horizontal velocity). The relationship of the three vectosr is presented as follows:

$$
\boldsymbol{U}_{\boldsymbol{a}}=\boldsymbol{U}_{\boldsymbol{o}}+\boldsymbol{U}_{\boldsymbol{h}}
$$


where $\boldsymbol{U}_{\boldsymbol{o}}(U, V), \boldsymbol{U}_{\boldsymbol{h}}\left(u_{h}, v_{h}\right)$ and $\boldsymbol{U}_{\boldsymbol{a}}\left(u_{a}, v_{a}\right)$ are the observed velocity, horizontal velocity and absolute velocity vector, respectively. As shown in Figure 9, horizontal rectification slightly enlarges the raw observed velocity in thermocline after typhoon passage.

(a) $U(\mathrm{~m} / \mathrm{s})$, B1

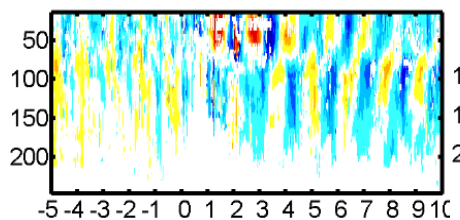

(d) $U_{a}(\mathrm{~m} / \mathrm{s}), \mathrm{B} 1$

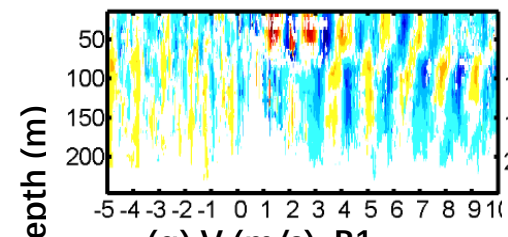

(g) $\mathrm{V}(\mathrm{m} / \mathrm{s}), \mathrm{B} 1$
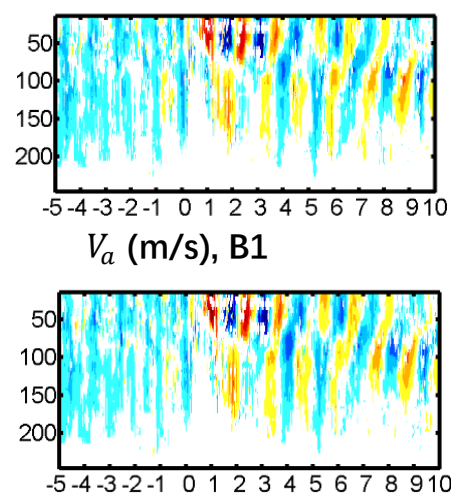

(b) $U(\mathrm{~m} / \mathrm{s}), B 2$

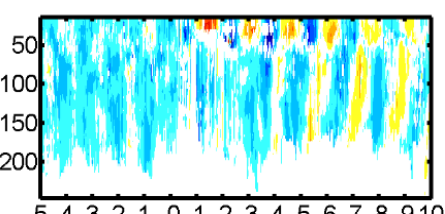

(e) $U_{a}(\mathrm{~m} / \mathrm{s}), \mathrm{B} 2$

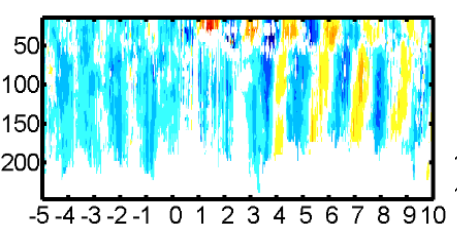

(h) $\mathrm{V}(\mathrm{m} / \mathrm{s}), \mathrm{B} 2$
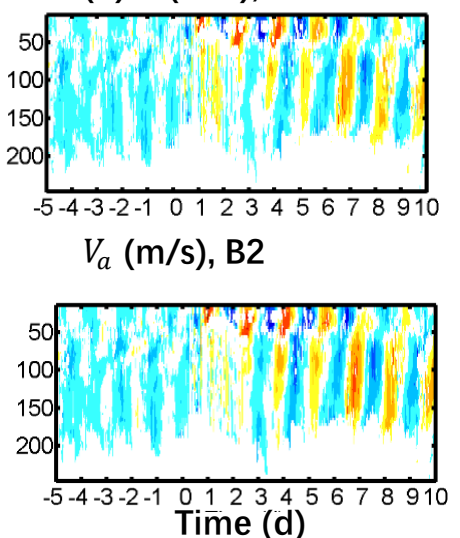

(c) $U(\mathrm{~m} / \mathrm{s}), B 4$

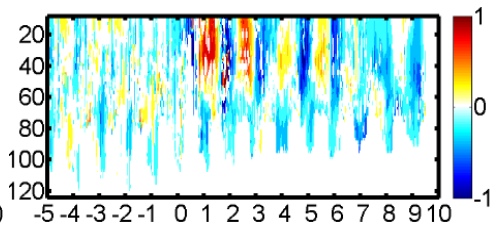

(f) $U_{a}(\mathrm{~m} / \mathrm{s})$, Buoy 4

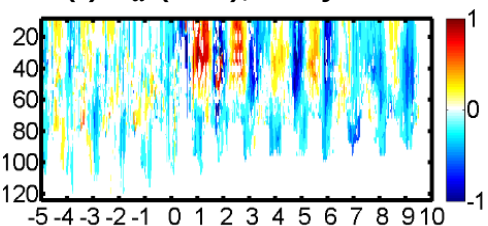

(i) $\mathrm{V}(\mathrm{m} / \mathrm{s}), B 4$

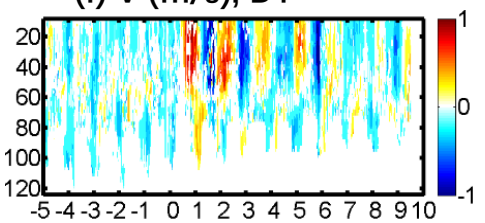

$V_{a}(\mathrm{~m} / \mathrm{s})$, B4

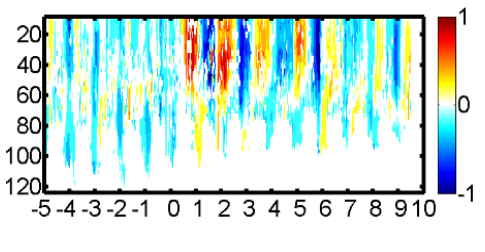

Figure 9. Zonal current velocity $\mathrm{U}$, zonal current velocity of horizontal rectification $U_{a}$, meridional velocity $\mathrm{V}$ meridional velocity of horizontal rectification $V_{a}$ on Buoys $1,2,4$. Abscissa represented days before (negative) and after (positive) Kalmaegi passing.

\subsubsection{Displacements and Tilt}

As shown in Figure 10, horizontal displacement of ADCP in mooring can reach $1500 \mathrm{~m}$, while the vertical horizontal can reach $\sim 200 \mathrm{~m}$, so the tilt is within the range of $10^{\circ}$. 
(a) $S_{h}$ and $S_{v}, \mathrm{M} 1$

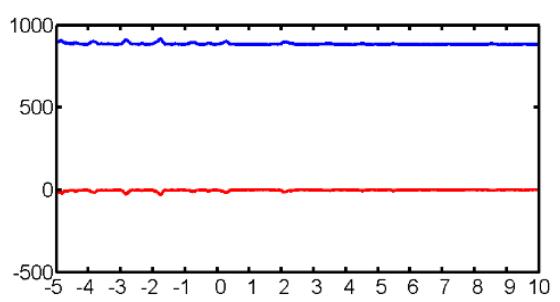

(c) $S_{h}$ and $S_{v}, \mathrm{M} 2$

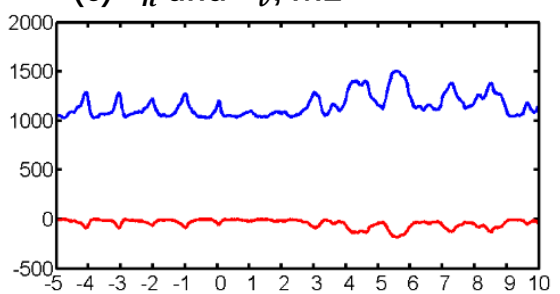

(e) $S_{h}$ and $S_{v}$, M5

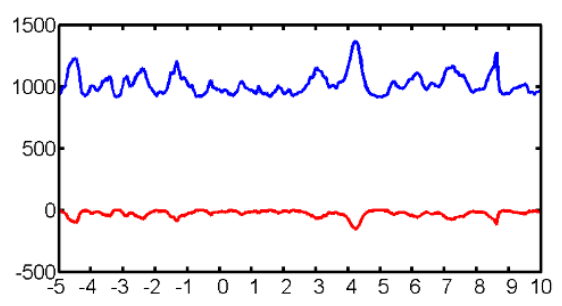

(b) $\theta, \mathrm{M} 1$

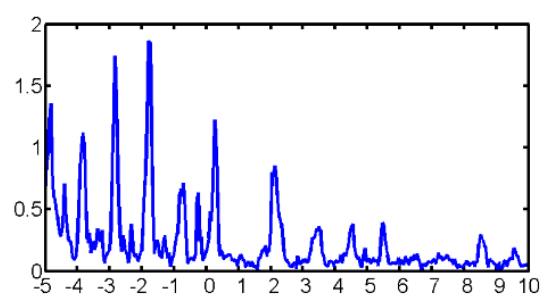

(d) $\theta, M 2$

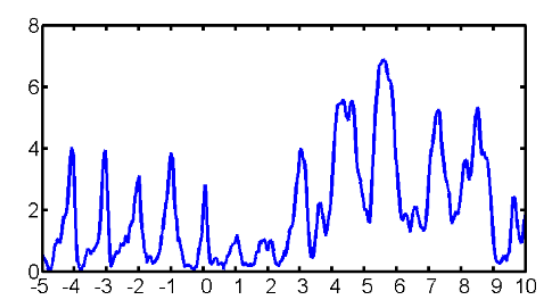

(f) $\theta, \mathrm{M} 5$

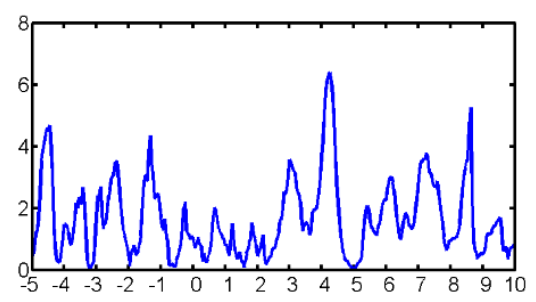

Time (d)

Figure 10. Horizontal displacement $S_{h}$ (blue), vertical displacement $S_{v}$ (red) and tilt $\theta$ of Mooring 1, 2, 5 (M1, M2, M5).

\subsubsection{Depth Rectification}

Based on the vertical record of ADCP data, the current velocity is conducted to depth rectification. As shown in Figure 11, there is more missing value of zonal velocity after depth rectification $U_{d}$ than missing value of zonal velocity before depth rectification $U_{n}$ in mixed layer and middle layer due to the upwards and downwards move of ADCP. Next, the bias of velocity before and after depth rectification (DRBU or DRBV) is used to estimate the depth rectification. As shown in Figure 12, DRBU or DRBV increases apparently at the depth lower than $400 \mathrm{~m}$ after the typhoon passage. The magnitude of DRB is mainly decided by the distance of station and track of typhoon $L$, while magnitude of velocity DRB is larger with smaller $L$. 
(a) $U_{n}(\mathrm{~m} / \mathrm{s}), \mathrm{M} 1$

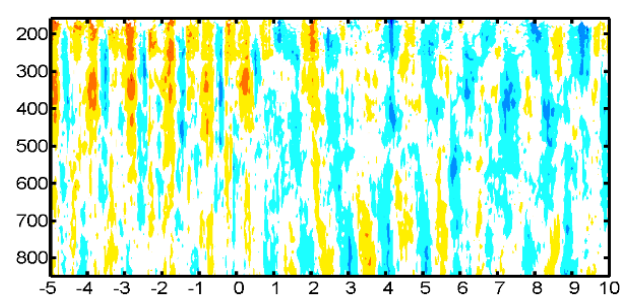

(c) $U_{n}(\mathrm{~m} / \mathrm{s}), \mathrm{M} 2$

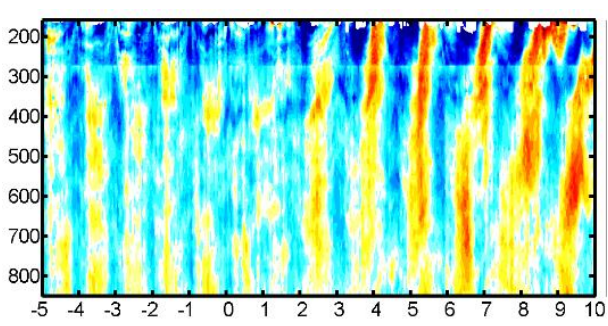

(e) $U_{n}(\mathrm{~m} / \mathrm{s}), \mathrm{M} 5$

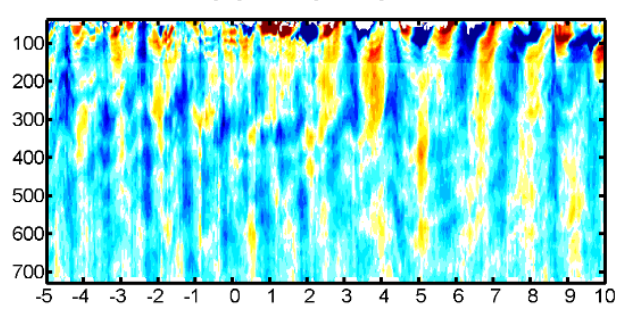

(b) $U_{d}(\mathrm{~m} / \mathrm{s}), \mathrm{M} 1$

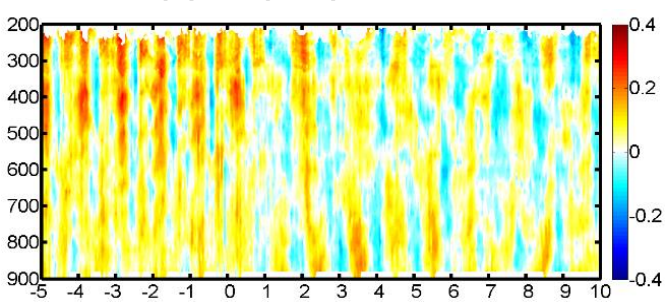

(d) $U_{d}(\mathrm{~m} / \mathrm{s}), \mathrm{M} 2$

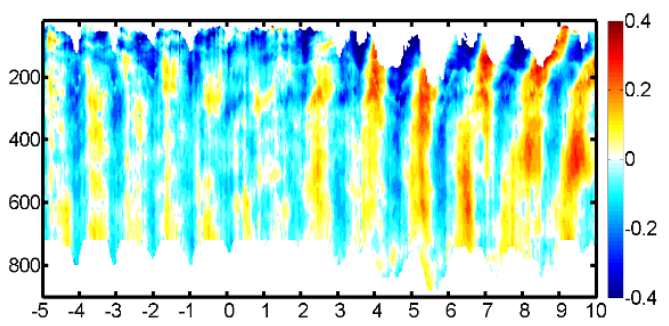

(f) $U_{d}(\mathrm{~m} / \mathrm{s}), \mathrm{M} 5$

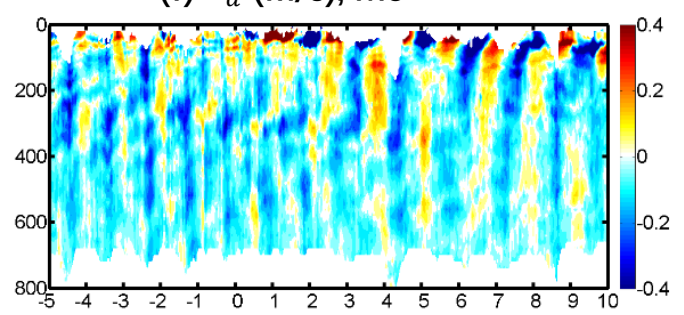

Figure 11. Zonal velocity before depth rectification $U_{n}$ and zonal velocity after depth rectification $U_{d}$ on Moorings 1, 2, 5 (M1, M2, M5) during Kalmaegi. The numbers on the abscissa noted the days. 
(a) $D R B U(\mathrm{~m} / \mathrm{s})$, M1

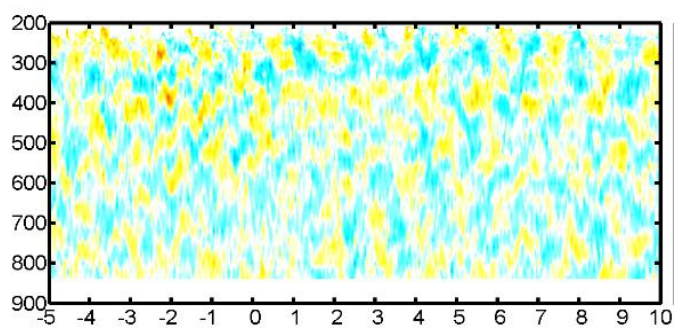

(c) $D R B U(\mathrm{~m} / \mathrm{s}), \mathrm{M} 2$

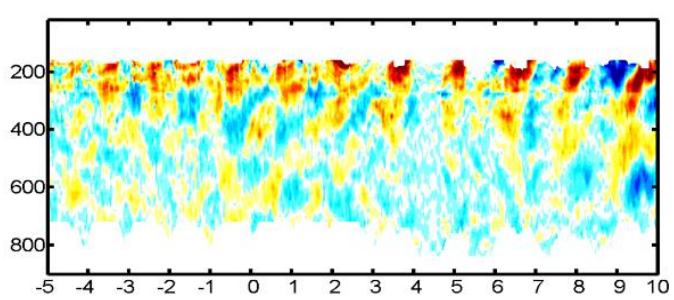

(e) $\boldsymbol{D R B U}(\mathrm{m} / \mathrm{s}), \mathrm{M} 5$

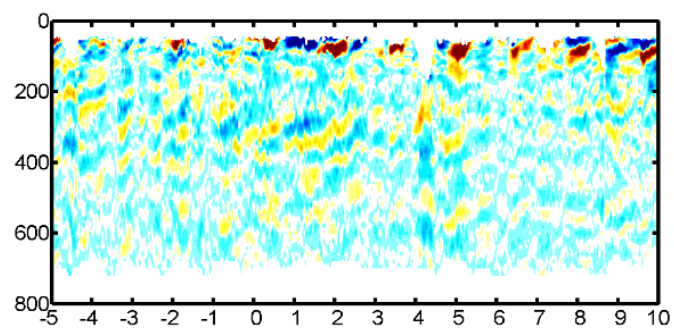

(b) $\operatorname{DRBV}(\mathrm{m} / \mathrm{s}), \mathrm{M} 1$

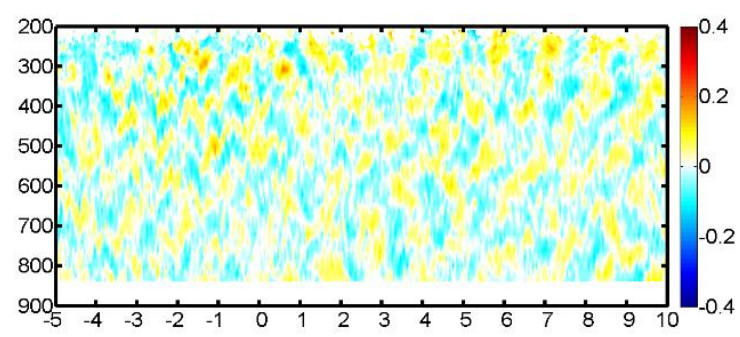

(d) $D R B V(\mathrm{~m} / \mathrm{s}), M 2$

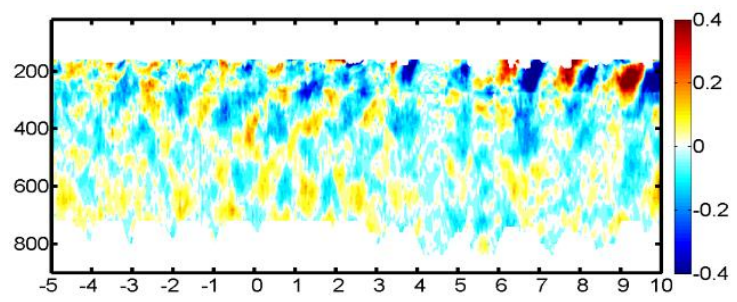

(f) $D R B V(m / s), M 5$

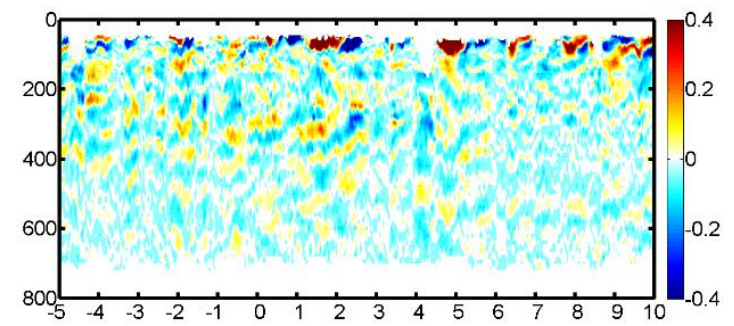

Figure 12. Depth rectification bias of zonal velocity $D R B U$ and depth rectification bias of meridional velocity $D R B V$ on Moorings 1, 2, 5 (M1, M2, M5). The numbers on the abscissa noted the days.

\subsubsection{Crosscheck}

The overlapping velocity of Buoys 2, 4 is used to crosscheck: the bias of velocity of buoy and mooring, and the correlation coefficient time series is calculated to check the consistent of the overlapping velocity. As shown in Figure 13, the zonal (meridional) velocity bias before depth rectification $U_{n b}\left(V_{n b}\right)$ is prominently larger than the zonal (meridional) velocity bias after depth rectification $U_{n b}\left(V_{n b}\right)$, especially after the passage of typhoon. Besides, the correlation coefficient of zonal (meridional) velocity $\gamma_{U}\left(\gamma_{V}\right)$ before depth rectification is prominently smaller than $\gamma_{U}\left(\gamma_{V}\right)$ after depth rectification. 
(a) $U_{n b}(\mathrm{~m} / \mathrm{s}), \mathrm{s} 2$

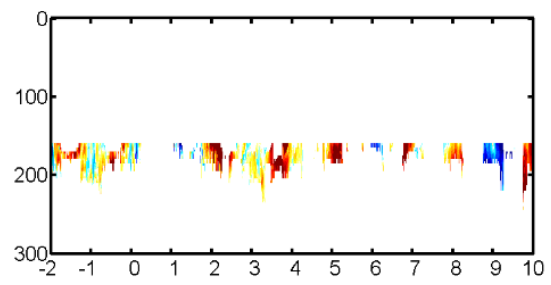

(c) $U_{d b}(\mathrm{~m} / \mathrm{s}), \mathrm{S} 2$

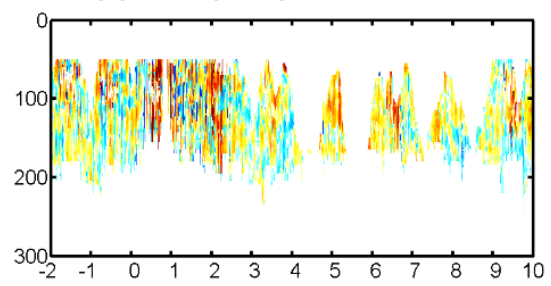

(e) $\gamma_{U}, \mathrm{~S} 2$

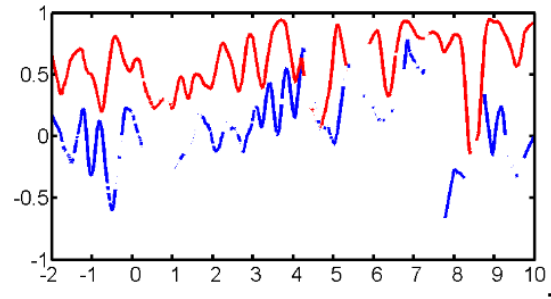

Time (d) (b) $V_{n b}(\mathrm{~m} / \mathrm{s}), \mathrm{s} 2$

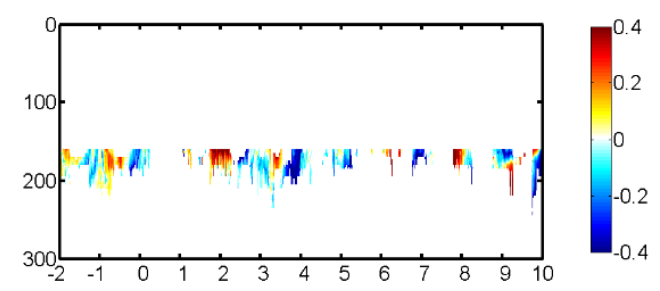

(d) $V_{d b}(\mathrm{~m} / \mathrm{s}), \mathrm{s} 2$

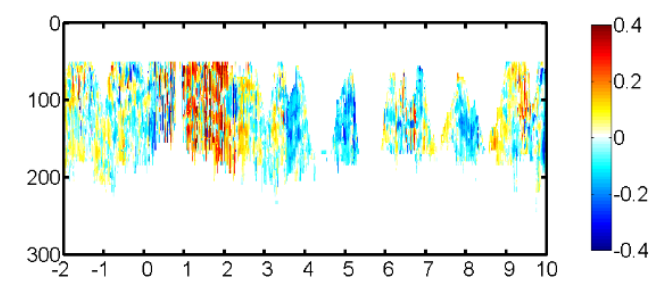

(f) $\gamma_{V}, \mathrm{~S} 2$

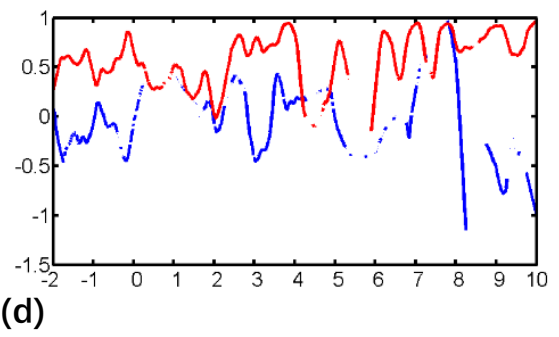

(g) $\boldsymbol{U}_{n b}(\mathrm{~m} / \mathrm{s}), \mathrm{S} 4$

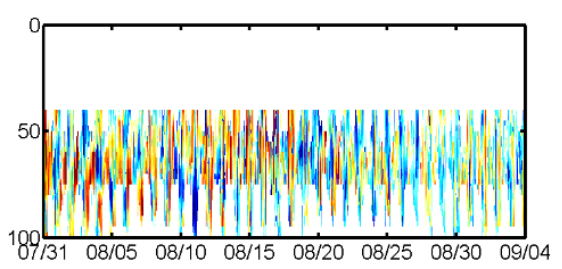

(i) $U_{d b}(\mathrm{~m} / \mathrm{s}), \mathrm{s} 4$

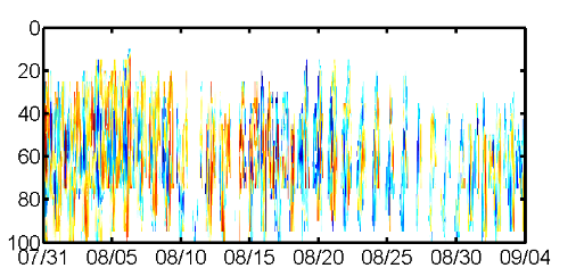

(k) $\gamma_{U}, \mathrm{~S} 2$

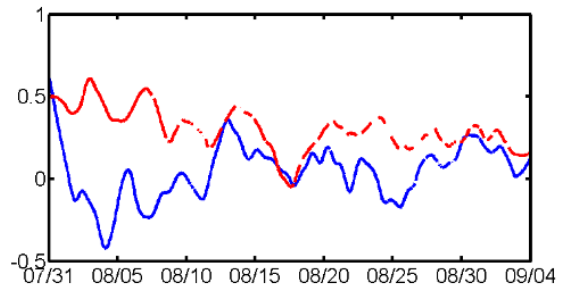

(h) $V_{n b}(\mathrm{~m} / \mathrm{s}), \mathrm{S} 4$

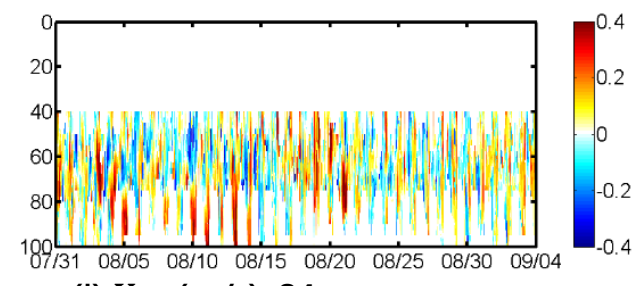

(j) $V_{d b}(\mathrm{~m} / \mathrm{s}), \mathrm{s} 4$

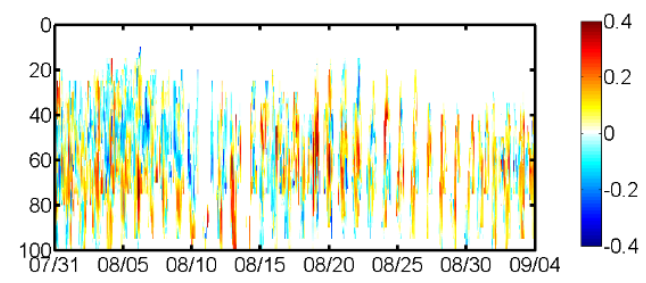

(k) $\gamma_{V}, \mathrm{~S} 2$

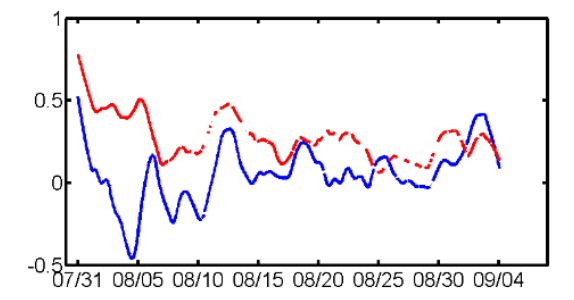

Time (Month/Day) 
Figure 13. Zonal (meridional) velocity bias before depth rectification $U_{n b}\left(V_{n b}\right)$. (c) Zonal (meridional) velocity bias after depth rectification $U_{n b}\left(V_{n b}\right)$. Correlation coefficient of zonal (meridional) velocity $\gamma_{U}\left(\gamma_{V}\right)$ before depth rectification (blue) and after depth rectification (red). Data sources from overlapping current velocity between Later 1 and Layers 2, 3 on Stations 2, 4 (S2, S4). Numbers on abscissa notes the day before (negative) and after (positive) typhoon Kalmaegi passing.

\section{Oceanic Response}

As shown in Figure 5, the cooling and saltier in mixed layer may due to the convection or less isolation during typhoon. At the same time, the mixed layer deepen, thermocline moves up and down after the passage of typhoon. As shown in Figure 6, the anomaly of temperature presents negatively and positively in thermocline due to the upwelling and downwelling at the top thermocline (Figure 17).

(a) $\Delta T_{n}\left({ }^{\circ} \mathrm{C}\right), \mathrm{B} 2$

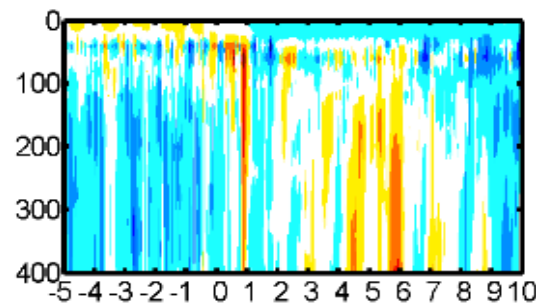

(c) $\Delta T_{n}\left({ }^{\circ} \mathrm{C}\right), \mathrm{B} 4$

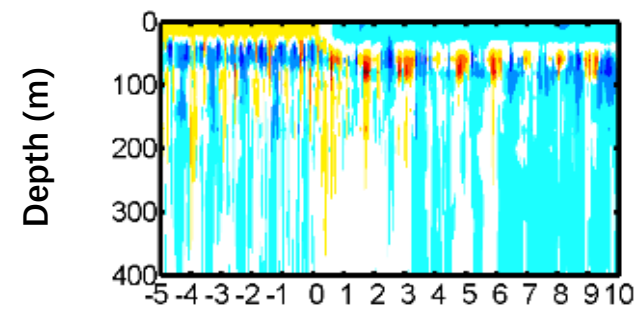

(e) $\Delta T_{n}\left({ }^{\circ} \mathrm{C}\right), \mathrm{B} 5$

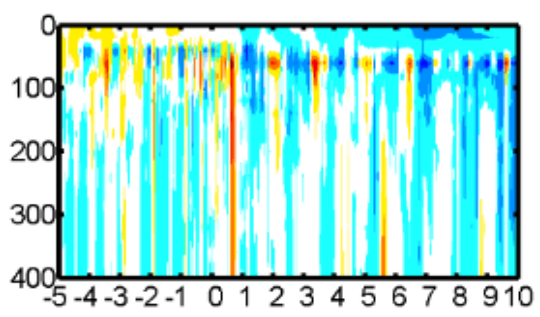

(b) $\Delta T_{d}\left({ }^{\circ} \mathrm{C}\right), \mathrm{B} 2$

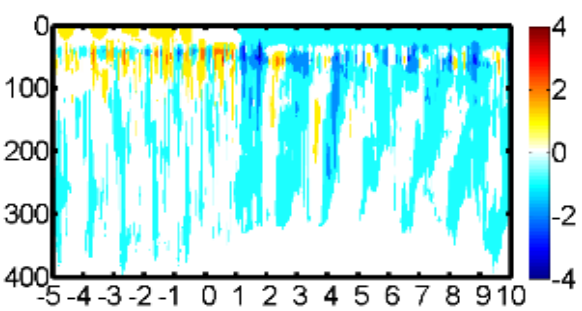

(d) $\Delta T_{d}\left({ }^{\circ} \mathrm{C}\right), \mathrm{B} 4$

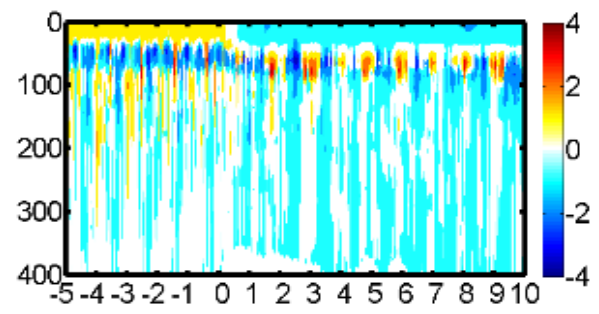

(f) $\Delta T_{d}\left({ }^{\circ} \mathrm{C}\right), \mathrm{B} 5$

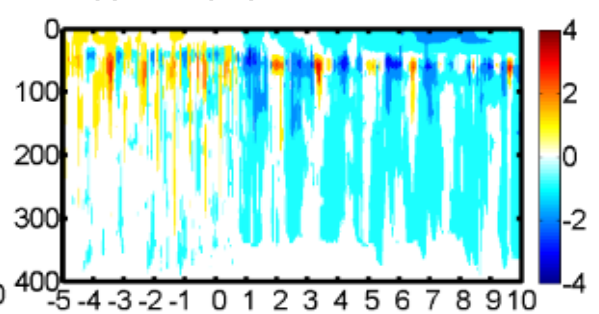

Time (d) 
(g) $\Delta S_{n}$ (psu), B2

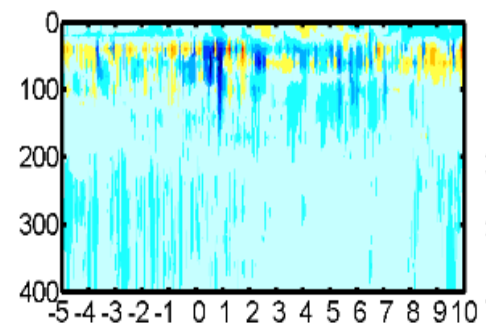

(i) $\Delta S_{n}$ (psu), B4

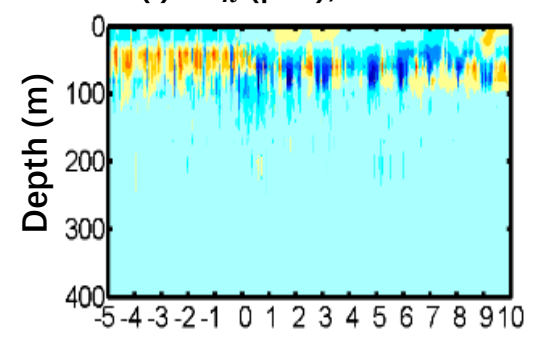

(k) $\Delta S_{n}$ (psu), B5

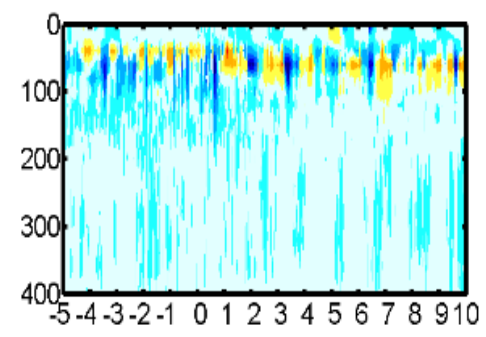

(h) $\Delta \boldsymbol{S}_{d}$ (psu), B2

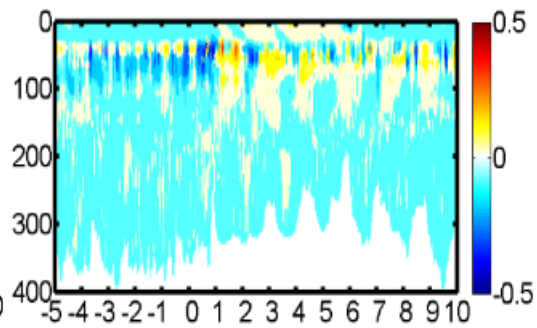

(j) $\Delta \boldsymbol{S}_{\boldsymbol{d}}$ (psu), B4

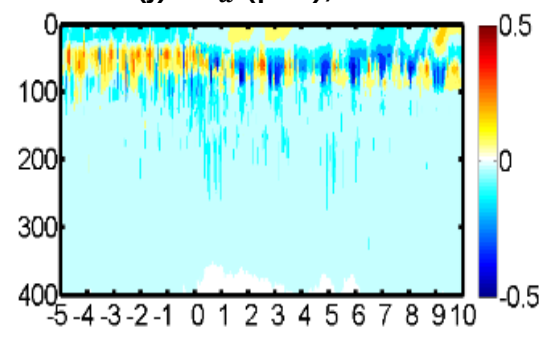

(I) $\Delta S_{d}$ (psu), B5

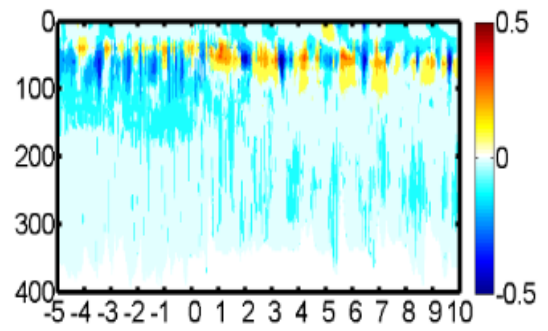

Time (d) (m) DRBT $\left({ }^{\circ} \mathrm{C}\right), \mathrm{B} 2$

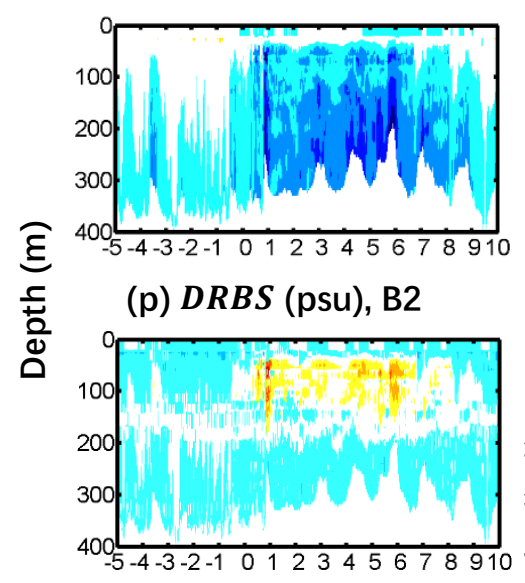

(n) $\mathrm{DRBT}\left({ }^{\circ} \mathrm{C}\right), \mathrm{B} 4$

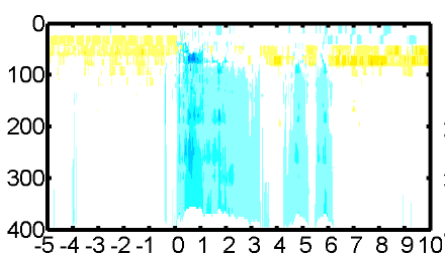

(q) DRBS (psu), B4

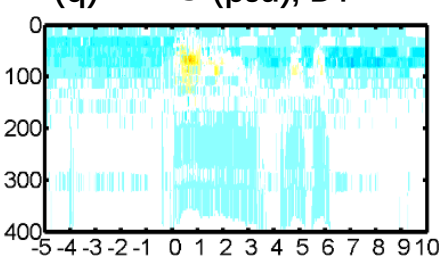

Time (d) (o) $\mathrm{DRBT}\left({ }^{\circ} \mathrm{C}\right), \mathrm{B} 5$

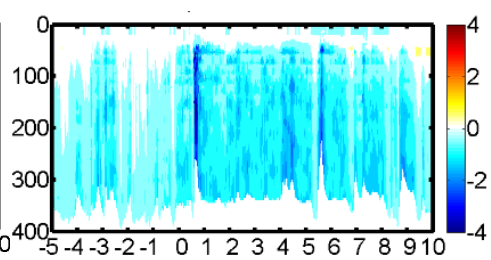

(r) DRBS (psu), B5

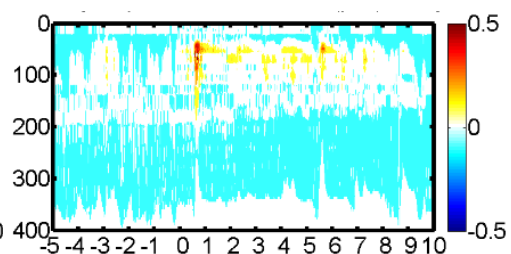


(s) B2

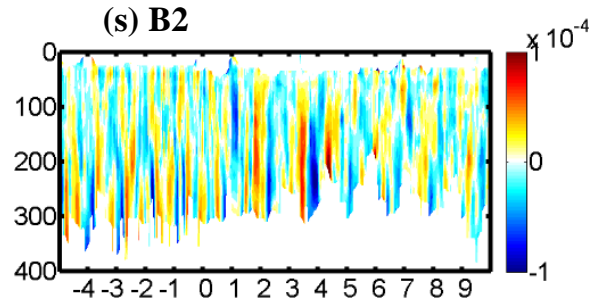

(u) $\mathbf{B 5}$

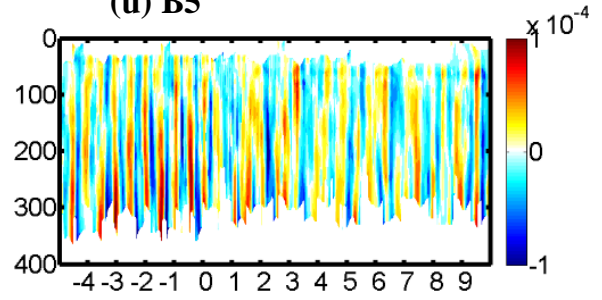

(t) $\mathbf{B} 4$

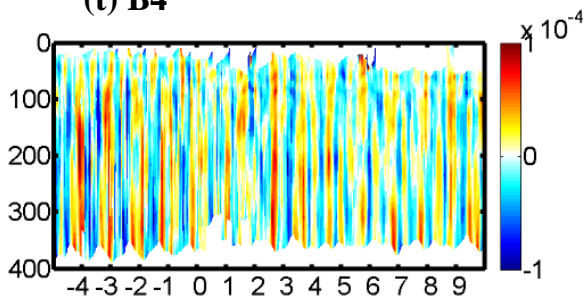

Time (d)

Figure 6. (a, c, e) Temperature anomaly before depth rectification $\Delta T_{n}$ and $(\mathbf{b}, \mathbf{d}, \mathbf{f})$ temperature anomaly after depth rectification $\Delta T_{d},(\mathbf{g}, \mathbf{i}, \mathbf{k})$ salinity anomaly before depth rectification $\Delta S_{n}$ and $(\mathbf{h}, \mathbf{j}, \mathbf{l})$ salinity anomaly after depth rectification $\Delta S_{d} .(\mathbf{m}, \mathbf{n}, \mathbf{o})$ Depth rectification bias of temperature $D R B T$ and $(\mathbf{p}, \mathbf{q}, \mathbf{r})$ depth rectification bias of salinity $D R B T$ on Buoys 2, 4, 5 (B2, B4, B5). (s, t, u) Upwelling (positive) and downwelling (negative) based on isolines of temperature during typhoon Kalmaegi. The numbers on the abscissa note the days before (negative) and after (positive) typhoon Kalmaegi, while 0 noted the day (9/15) Kalmaegi passing stations.

As shown in Figure 14 and Figure 15, typhoon motivates $0.4 \mathrm{~m} / \mathrm{s}$ near-inertial current in mixed layer with upward phase and downward energy. The persistence time of near-inertial is deemed as the current with the near phase and magnitude. The persistence time of nearinertial current and its propagation depth are closely related to typhoon intensity, distance to typhoon track, and background current. As shown in Table 1, the persistence time may be more closely related to intensity of typhoon, for example, the persistence time of Rammasun with category III can reach $40 \mathrm{~d}$ on Station 1, which is larger than that of Kalmaegi with category II. The propagation depth of near-inertial current is deeper when it is closer to typhoon track, for example, the propagation depth on Buoy 2 during Rammasun is larger than that of Buoys 1, 4, 5. Besides, the propagation depth of Sarika on Station 7 can propagate to sea bottom may due to the small interference of background current. 
(a) $\mathrm{U}(\mathrm{m} / \mathrm{s}), \mathrm{S1}$

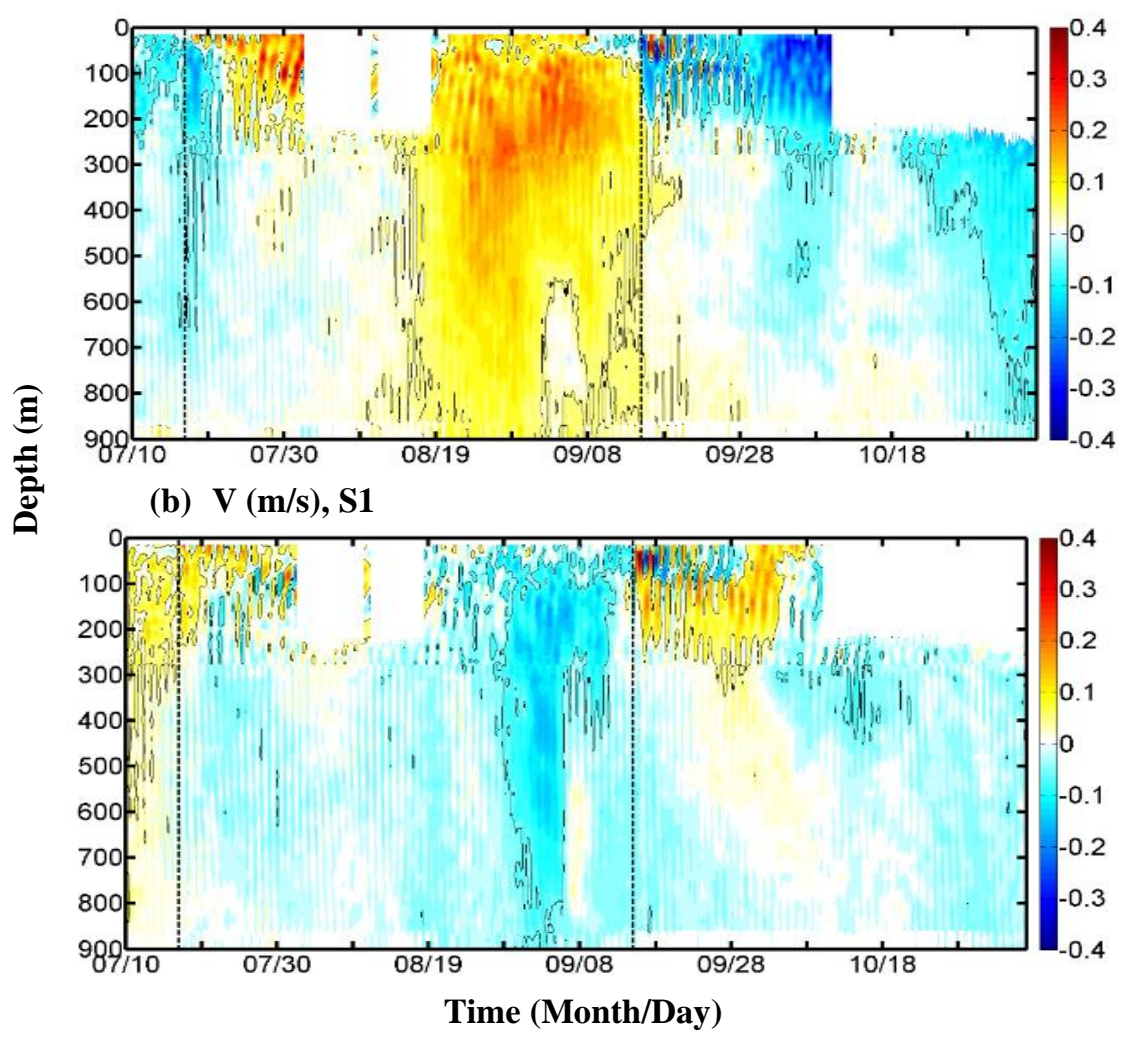

(c) $\mathrm{U}(\mathrm{m} / \mathrm{s}), \mathbf{S 2}$

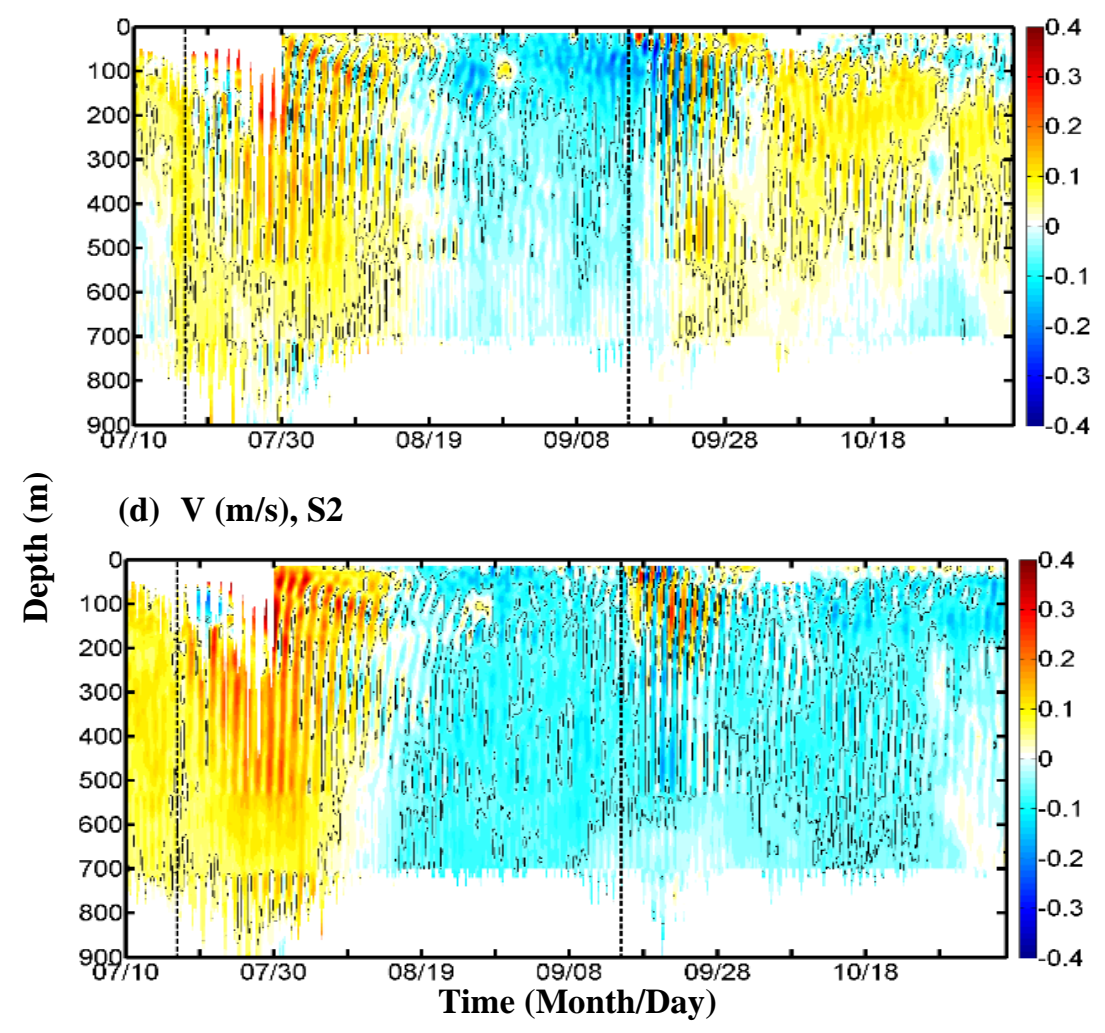


(e) $\mathrm{U}(\mathrm{m} / \mathrm{s}), \mathrm{S4}$

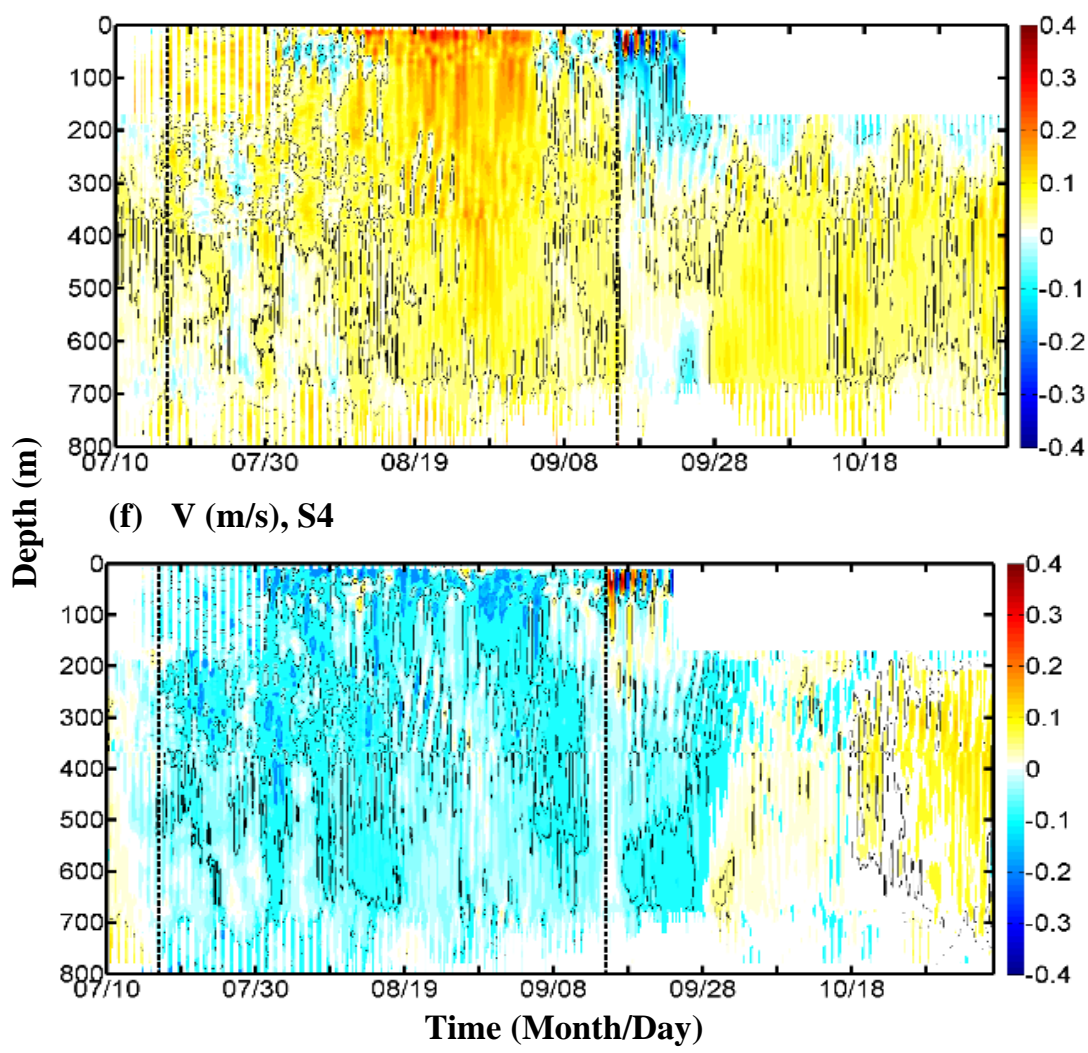


(g) U (m/s), S5

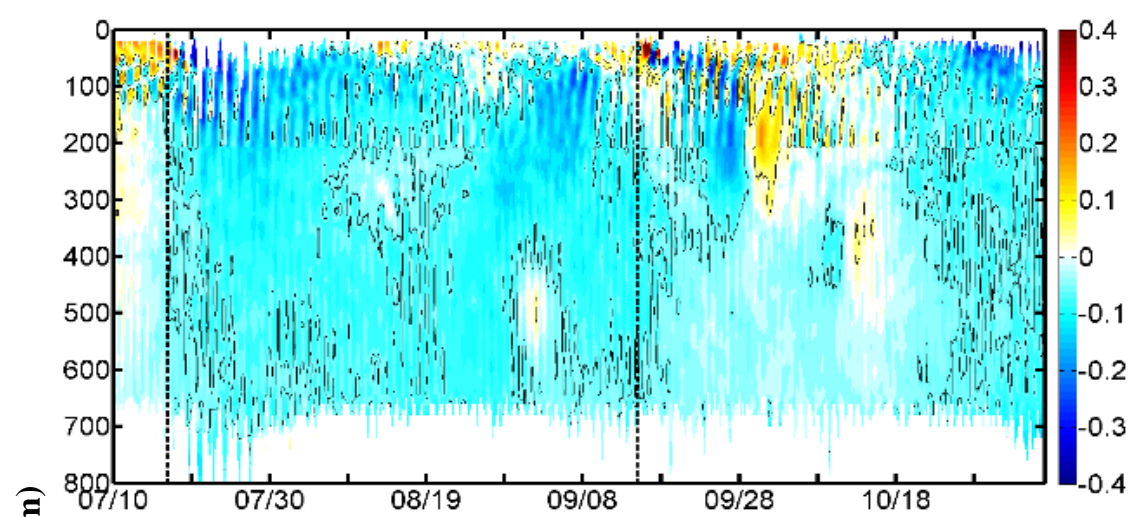

(h) $\mathrm{V}(\mathrm{m} / \mathrm{s}), \mathrm{S5}$

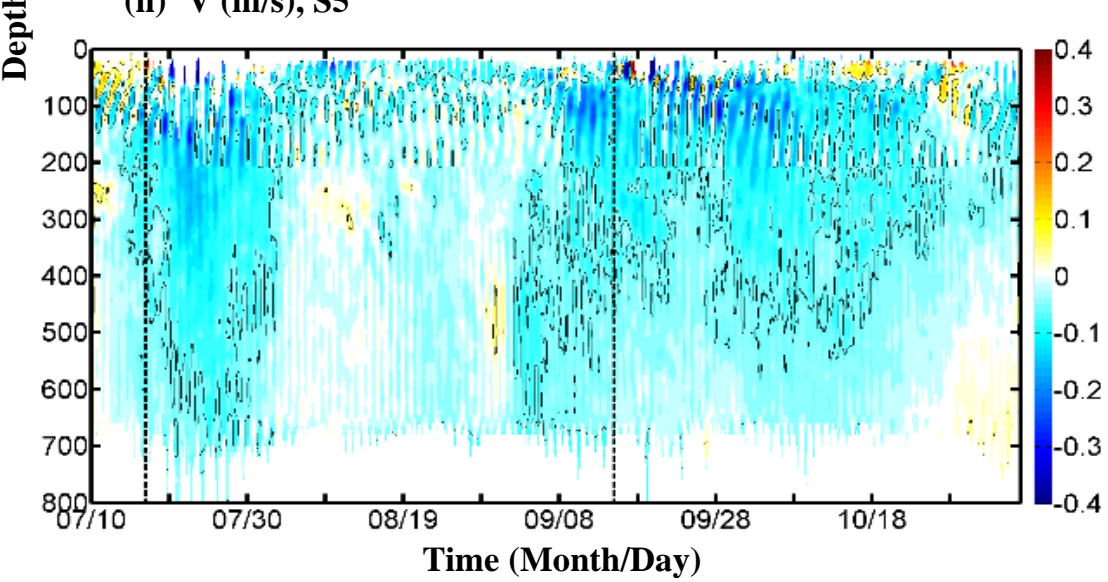

(i) $\mathrm{U}(\mathrm{m} / \mathrm{s}), \mathrm{S6}$

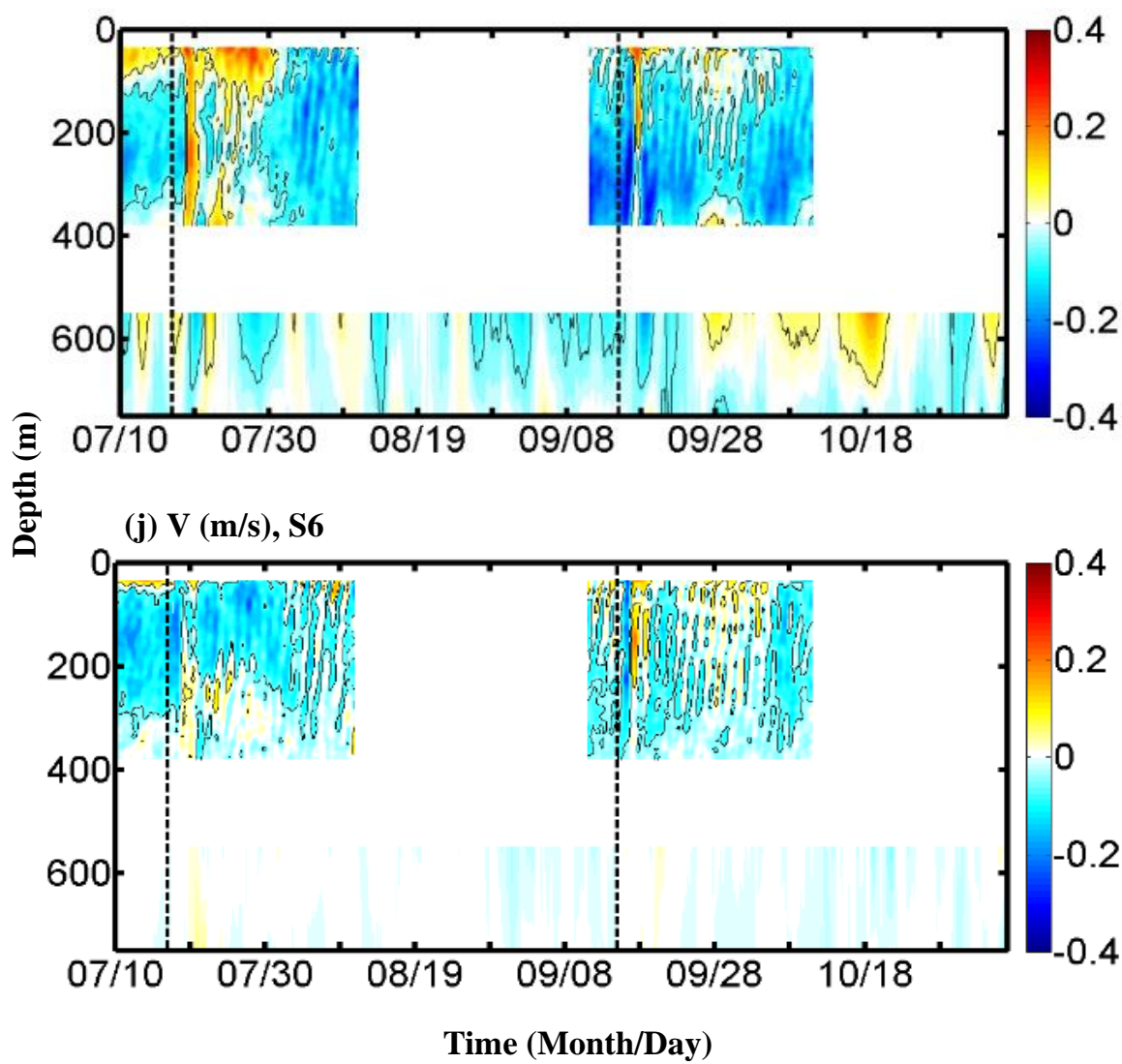


(k) KE $\left(\mathrm{J} / \mathrm{m}^{3}\right), \mathrm{S1}$

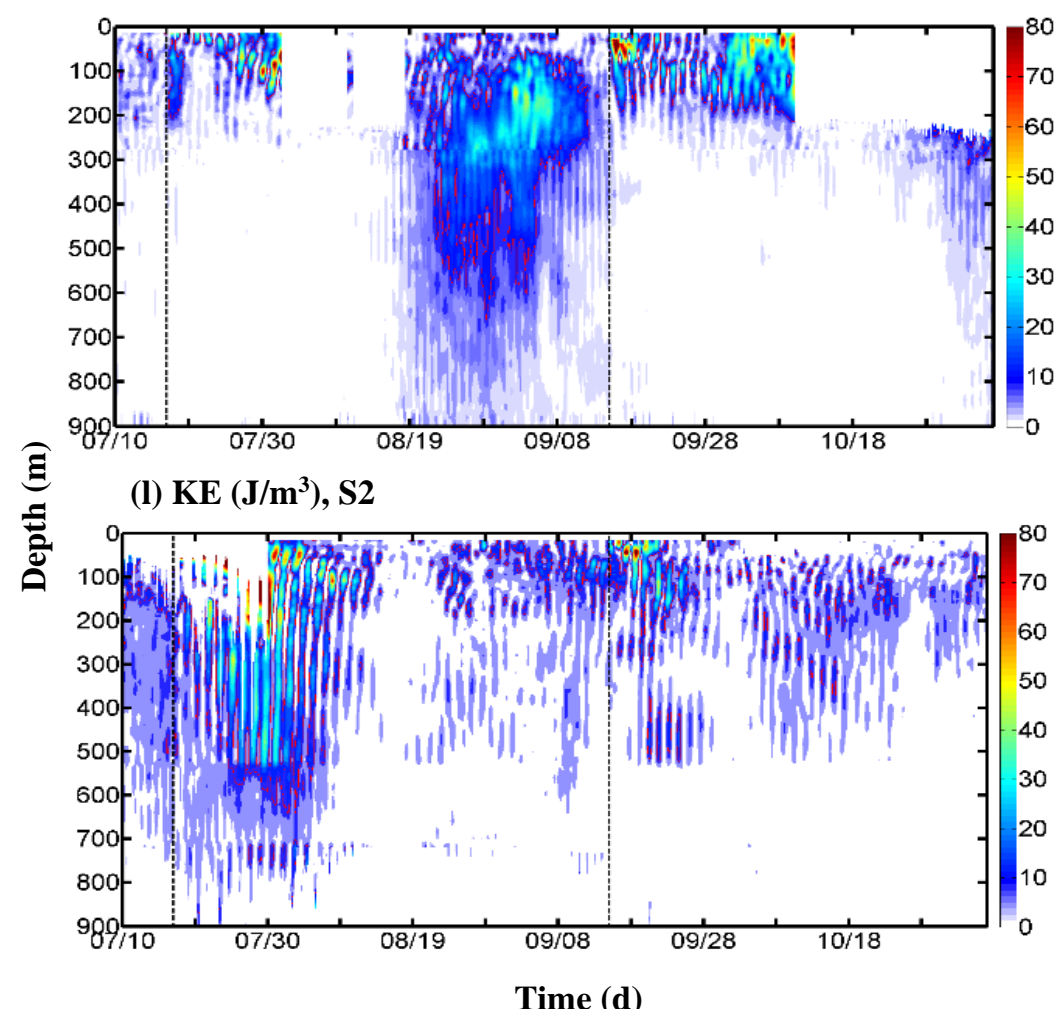

(m) KE $\left(\mathrm{J} / \mathrm{m}^{3}\right), \mathbf{S 4}$

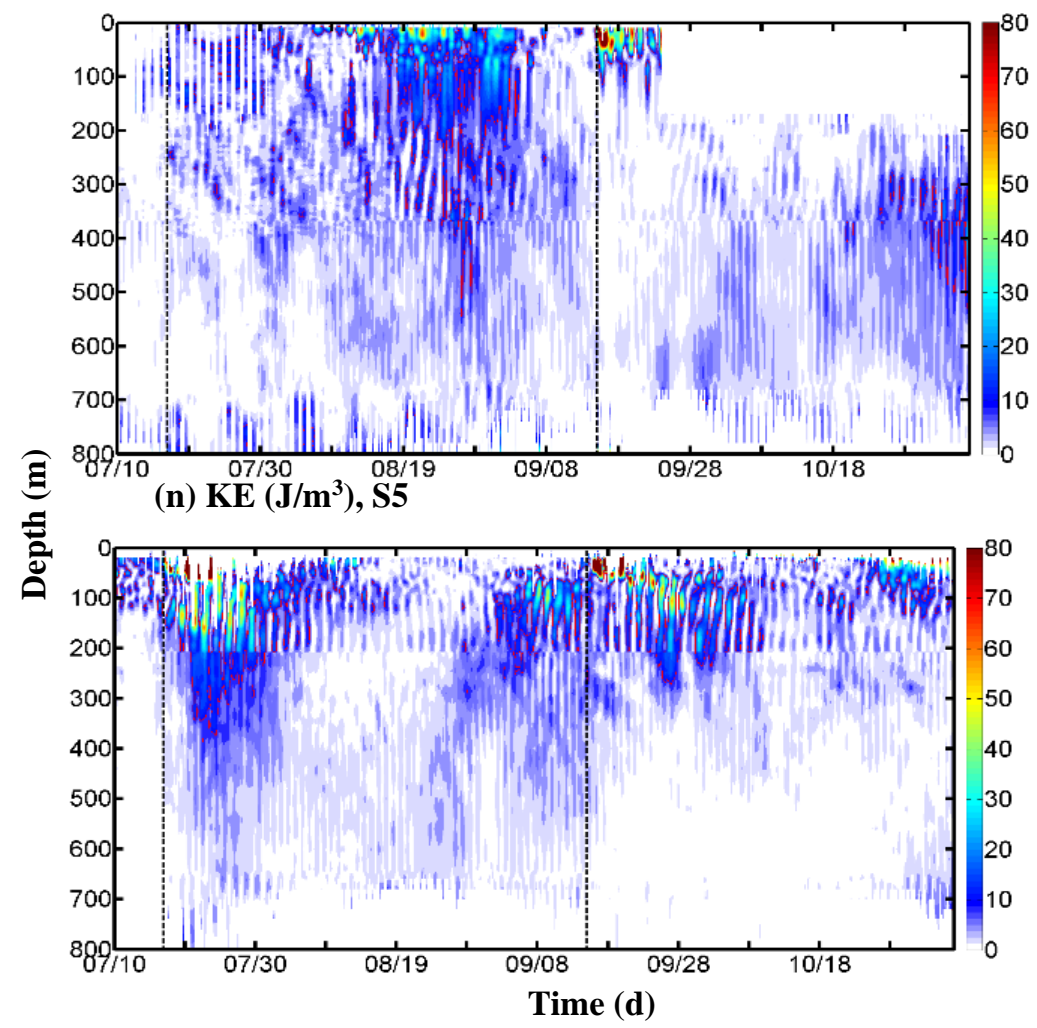


(o) $\mathrm{KE}\left(\mathrm{J} / \mathrm{m}^{3}\right)$, S6

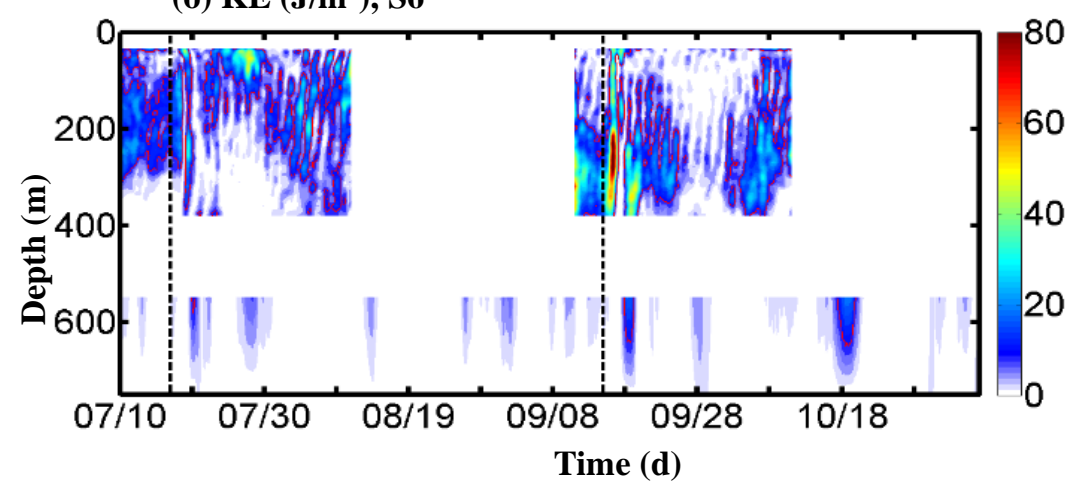

Figure 14. The zonal current velocity after depth and horizontal rectification $U$, meridional current velocity after depth and horizontal rectification $\mathrm{V}$, kinetic energy KE during the successive typhoon Rammasun and Kalmaegi in 2014 on Stations (1, 2, 4, 5, 6). Isoline on (a-j) is $\pm 0.05,10$ on $(\mathrm{k}-\mathrm{o})$. 
(a) $\mathrm{U}(\mathrm{m} / \mathrm{s}), \mathrm{S} 7$

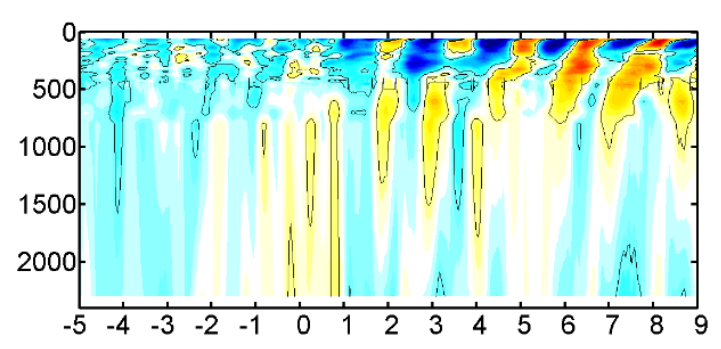

(c) $\mathrm{U}(\mathrm{m} / \mathrm{s}), \mathbf{S 8}$

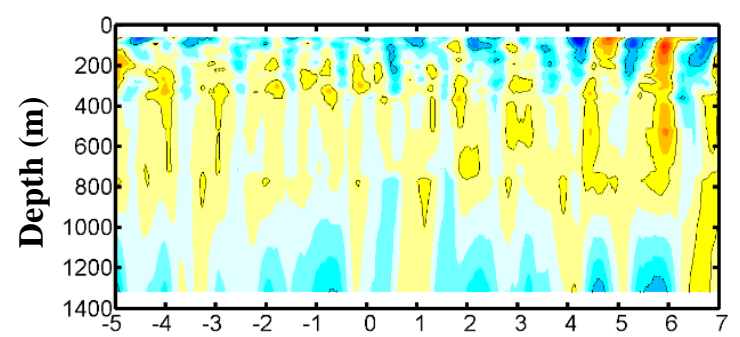

(e) $\mathrm{KE}\left(\mathrm{J} / \mathrm{m}^{3}\right), \mathrm{S} 7$

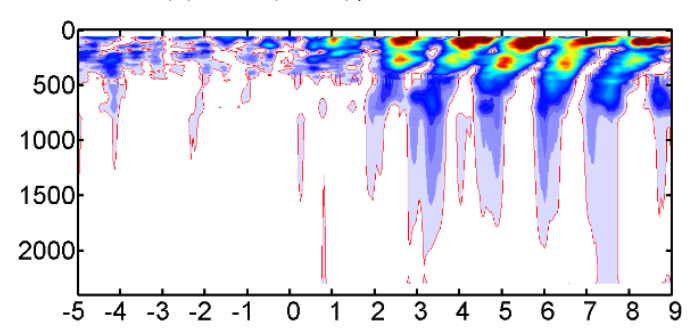

(b) $\mathrm{V}(\mathrm{m} / \mathrm{s}), \mathrm{S} 7$

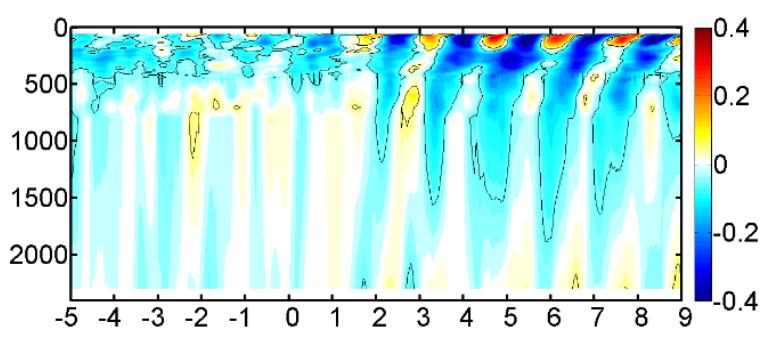

(d) $\mathrm{V}(\mathrm{m} / \mathrm{s})$, $\mathrm{S8}$

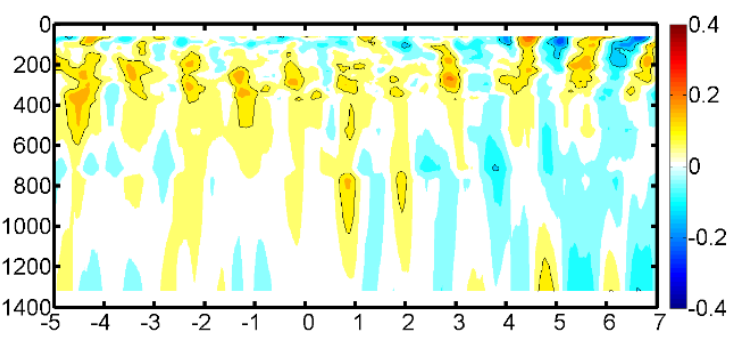

(f) $\mathrm{KE}\left(\mathrm{J} / \mathrm{m}^{3}\right), \mathrm{S8}$

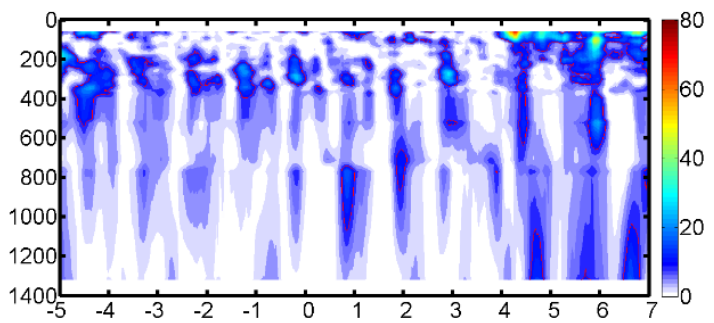

Time (d)

Figure 15. Zonal current velocity after depth rectification $U$, meridional current velocity after depth rectification V, kinetic energy KE on Stations 7-8 (S7-8) during Sarika. Isoline on (a-d) is $0.1,2$ on (e), 10 on (f). Numbers on abscissa note time before (negative) and after (positive) typhoon passing.

Table 1. Persistence Time $T_{p}$ and propagation depth $D_{p}$ of kinetic energy during Rammasun, Kalmaegi and Sarika (see, Figure 14, Figure 15).

\begin{tabular}{lllll}
\hline & Rammasun & \multicolumn{3}{l}{ Kalmaegi } \\
\hline & $T_{p}$ & $D_{p}$ & $T_{m}$ & $D_{p}$ \\
\hline S1 & 40 & 200 & 15 & 200 \\
S2 & 30 & 800 & 15 & 600 \\
S4 & 25 & 200 & 20 & 200 \\
S5 & 30 & 400 & 25 & 300 \\
S6 & 25 & 600 & 15 & 650 \\
\hline \multicolumn{5}{r}{ Sarika } \\
\hline S7 & $T_{p}$ & $D_{p}$ & \\
S8 & $/$ & 2400 & \\
\hline
\end{tabular}




\section{Conclusions}

During typhoon passage, strong currents and winds induced horizontal and vertical displacements, as well as tilt of instruments, bringing bias to observed data of CTDs and ADCPs. The algorithms are proposed to calculate the displacements and tilt of instruments. The results show that the horizontal displacement reaches $2000 \mathrm{~m}$ in surface and decreases with increasing depth, while vertical displacement increases with the increase of depth, which can $200 \mathrm{~m}$ in thermocline. The tilt of instruments increase with the increase of depth and the maximum tilt can reach $10^{\circ}$ on moorings. The displacements and tilt of instrument on buoy is larger than that on mooring.

There is more missing value after depth rectification in thermocline. The temperature anomaly after depth rectification can correctly inflect cooling of thermocline. The salinity anomaly after depth rectification is constrained to depth lower $100 \mathrm{~m}$. The depth rectification bias of temperature (DRBT) can reach $4{ }^{\circ} \mathrm{C}$ in thermocline, while depth rectification bias of salinity can reach $0.5 \mathrm{psu}$ in mixed layer.

The horizontal velocity of buoys can reach $0.2 \mathrm{~m} / \mathrm{s}$. The buoy velocity is conducted to horizontal rectification. The current velocity is slightly enlarged after horizontal rectification after passage of typhoon in thermocline. The velocity of mooring is conducted to depth rectification. The bias caused by vertical movement of instruments is concentrated in the layer above $400 \mathrm{~m}$, which can reach as much as $0.4 \mathrm{~m} / \mathrm{s}$. The crosscheck of overlapping velocity shows that the bias and correlation coefficient of overlapping velocity after depth rectification is smaller than that before depth rectification, especially after the passage of typhoon. In a word, depth rectification improves the quality of data, especially during the typhoons.

The oceanic response is analyzed base on the rectified data. Typhoon can cool the mixed layer water as much as $1.3^{\circ} \mathrm{C}, 0.03 \mathrm{psu}$ (Figure 16). The mixed layer can deepen by $25 \mathrm{~m}$, the thermocline moves up and down due to the upwelling and downwelling. On the other hand, typhoon motivates 0.4 near-inertial current in mixed layer with upward phase and downward energy propagation. The upwelling and downwelling can reach $10^{-4} \mathrm{~m} / \mathrm{s}$ at bottom thermocline during typhoon. The persistence time of near-inertial current can reach $40 \mathrm{~d}$. The vertical propagation of near-inertial waves is deeper when it is closer to typhoon track. The small interface of abyssal current allows the kinetic energy propagate longer, and its propagation depth can reach the $2400 \mathrm{~m}$ sea bottom. 
(a) Temperature $\left({ }^{\circ} \mathrm{C}\right), \mathrm{B} 2$

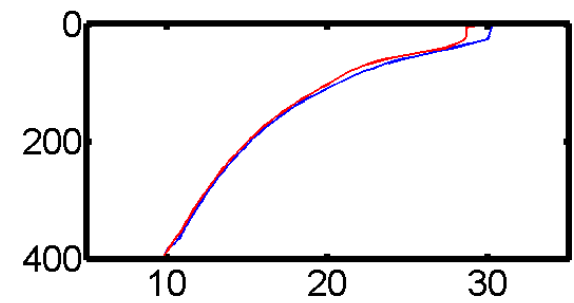

(c) Temperature $\left({ }^{\circ} \mathrm{C}\right), \mathrm{B} 4$

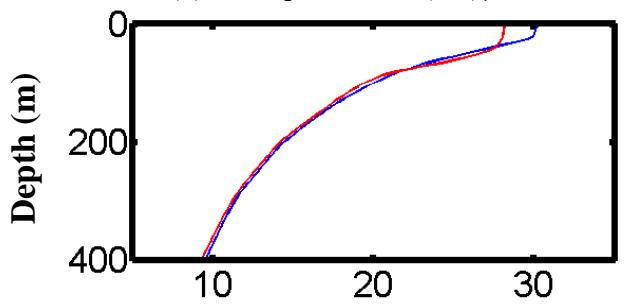

(e) Temperature $\left({ }^{\circ} \mathrm{C}\right), \mathrm{B5}$

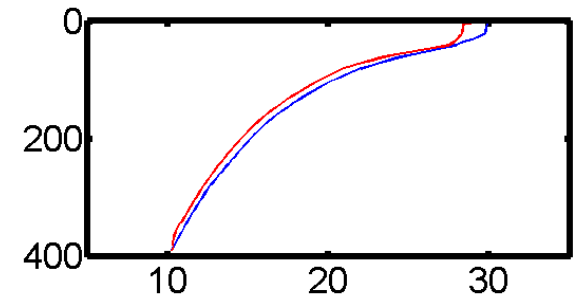

(b) Salinity (psu), B2

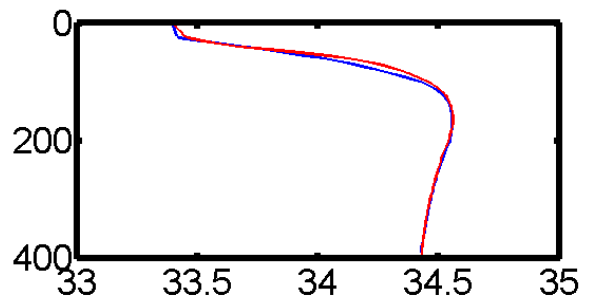

(d) Salinity (psu), B4

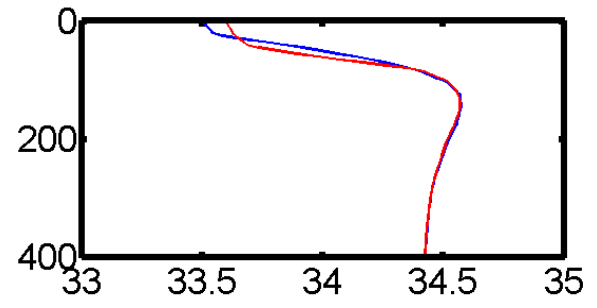

(f) Salinity (psu), B5

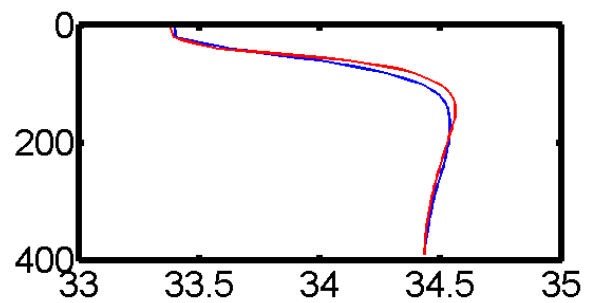

Figure 16. Depth-averaged temperature and salinity before (blue) and after (red) Kalmaegi passing. Cooling of Buoys 2, 4, 5 in mix layer (lower than $50 \mathrm{~m}$ ) is 1.1, 1.3, $1.1^{\circ} \mathrm{C}$, respectively, and thermocline (deeper than $50 \mathrm{~m}$ ) is $0.2,0.4,0.6^{\circ} \mathrm{C}$, respectively. Fresh of Buoys $2,4,5$ in mix layer (lower than $50 \mathrm{~m}$ ) is $0.003,-0.02,0.03 \mathrm{psu}$, respectively, and thermocline (deeper than 50 $\mathrm{m})$ is prec-0.01, 0.01, $-0.02 \mathrm{psu}$, respectively.

Author Contributions: Han Zhang constructs an original structure of this paper. Zhixiong Yao, Zheqi Shen. and Di Tian provide a deep insight for influence of atmosphere. Dongfeng Xu and Chenghao Yang provide the oceanic data of Mooring 6. Youmin Tang and Juncheng Zuo fund the observations of other stations.

Funding: This study is funded by the National Key R\&D Program of China (2017YFA0604202), the National Programme on Global Change and Air-Sea Interaction (GASI-IPOVAI-04), the National Natural Science Foundation of China ( 41621064), the National Natural Science Foundation of China (41806021, 41730535, 41705048, 41621064), the Scientific Research Fund of the Second Institute of Oceanography, MNR (JG1813), the China Ocean Mineral Resources Research and Development Association Program (DY135-E2-3-01), the National Key Research and Development Program of China (2018YFC1506403, 2016YFC1401605).

Acknowledgments: I appreciate the construction of H.Z. and the other coauthors' work, the best track and maximum sustained wind speed of JTWC, JMA and JMA. 


\section{References}

1. Price, J. F., 1981: Upper ocean response to a hurricane. J. Phys. Oceanogr., 11, 153-175, https://doi.org/10.1175/1520-0485(1981)011\%3C0153:UORTAH\%3E2.0.CO;2.

2. Price, J. F., 1983: Internal wave wake of a moving storm. Part I: scales, energy budget and observations. J. Phys. Oceanogr., 13, 949-965, https://doi.org/10.1175/1520-0485(1983)0132.0.CO;2

3. Price, J. F., R. A. Weller, and R. Pinkel, 1986: Diurnal cycling: observations and models of the upper ocean response to diurnal heating, cooling, and wind mixing. J. Geophys. Res. Oceans, 91, https://doi.org/10.1029//C091iC07p08411

4. Vincent, E. M., G. Madec, M. Lengaigne, J. Vialard, and A. Koch-Larrouy, 2013: Influence of tropical cyclones on sea surface temperature seasonal cycle and ocean heat transport. Clim. Dyn., 41, 2019-2038, https://doi.org/10.1007/s00382-012-1556-0.

5. Bueti, M. R., I. Ginis, L. M. Rothstein, and S. M. Griffies, 2014: Tropical cyclone-induced thermocline warming and its regional and global impacts. J. Clim., 27, 6978-6999, https://doi.org/10.1175/JCLI-D-14-00152.1.

6. Lucas, N. S., J. H. Simpson, T. P. Rippeth, and C. P. Old, 2014: Measuring turbulent dissipation using a tethered ADCP. J. Atmos. Ocean. Technol., 31, 1826-1837, https://doi.org/10.1175/JTECH-D13-00198.1.

7. Wu, L., B. Wang, and S. Geng, 2005: Growing typhoon influence on East Asia. Geophys. Res. Lett., 32, 109-127, https://doi.org/10.1029/2005GL022937.

8. Zhang, H., D. Chen, L. Zhou, X. Liu, T. Ding, and B. Zhou, 2016: Upper ocean response to Typhoon Kalmaegi (2014). J. Geophys. Res. Oceans, 121, 6520-6535, https://doi.org/10.1002/2016JC012064.

9. Zhang, H., and Coauthors, 2018: Net modulation of upper ocean thermal structure by Typhoon Kalmaegi (2014). J. Geophys. Res. Oceans, 123, 7154-7171, https://doi.org/10.1029/2018JC014119.

10. Zhang, H., and Coauthors, 2019: Ocean response to successive Typhoons Sarika and Haima (2016) based on data acquired via multiple satellites and moored array. Remote Sens. 11, 2360, https://doi.org/10.3390/rs11202360.

11. Wang, G., L. Wu, N. C. Johnson, and Z. Ling (2016), Observed three-dimensional structure of ocean cooling induced by Pacific tropical cyclones, Geophys. Res. Lett., 43, 7632-7638, https://doi.org/10.1002/2016GL069605.

12. Emanuel, K., 2001: Contribution of tropical cyclones to meridional heat transport by the oceans. J. Geophys. Res. Atmos., 106, 14771-14781, https://doi.org/10.1029/2000JD900641.

13. Perigaud, C, 2003: Impact of interannual rainfall anomalies on Indian Ocean salinity and temperature variability. J. Geophys. Res. 108, 3319, https: doi.org/ 10.1029/2002jc001699

14. Neetu, S., M. Lengaigne, E. M. Vincent, J. Vialard, G. Madec, G. Samson, M. R. Ramesh Kumar, and F. Durand, 2012: Influence of upper-ocean stratification on tropical cyclone-induced surface cooling in the Bay of Bengal. J. Geophys. Res. Oceans, 117, C12020, https://doi.org/10.1029/2012JC008433.

15. Reul, N., and Coauthors, 2014: Sea surface salinity observations from space with the SMOS satellite: A new means to monitor the marine branch of the water cycle. Surv. Geophys., 35, 681-722, https://doi.org/10.1007/s10712-013-9244-0. 
16. Greatbatch, R. J., 1983: On the response of the ocean to a moving storm: the nonlinear dynamics. J. Phys. Oceanogr., 13, 357-367, https://doi.org/10.1175/15200485(1983)013\%3C0357:OTROTO\%3E2.0.CO;2.

17. Price, J. F., T. B. Sanford, and G. Z. Forristall, 1994: Forced stage response to a moving hurricane. J. Phys. Oceanogr., 24, 233-260, https://doi.org/10.1175/15200485(1994)024\%3C0233:fsrtam\%3E2.0.co;2

18. Chen, F., Y. Du, L. Yan, D. Wang, and P. Shi, 2010: Response of upper ocean currents to typhoons at two ADCP moorings west of the Luzon Strait. Chin. J. Ocean. Limnol., 28, 1002-1011, https://doi.org/10.1007/s00343-010-0025-z.

19. Walker, N. D., R. R. Leben, and S. Balasubramanian, 2005: Hurricane-forced upwelling and chlorophyll $a$ enhancement within cold-core cyclones in the Gulf of Mexico. Geophys. Res. Lett., 32, https://doi.org/10.1029/2005GL023716.

20. Alford, M. H., and M. C. Gregg, 2001: Near-inertial mixing: Modulation of shear, strain and microstructure at low latitude. J. Geophys. Res. Oceans, 106, 16947-16968, https://doi.org/10.1029/2000JC000370.

21. Huang, S. M., and L. Y. Oey, 2015: Right-side cooling and phytoplankton bloom in the wake of a tropical cyclone. J. Geophys. Res. Oceans, 120, 5735-5748, https://doi.org/10.1002/2015JC010896.

22. Xu, Y., H. He, J. Song, Y. Hou, and F. Li, 2017: Observations and modeling of typhoon waves in the South China Sea. J. Phys. Oceanogr., 47, 1307-1324, https://doi.org/10.1175/JPO-D-16-0174.1.

23. Alford, M. H., M. F. Cronin, and J. M. Klymak, 2012: Annual cycle and depth penetration of windgenerated near-inertial internal waves at Ocean Station Papa in the Northeast Pacific. J. Phys. Oceanogr., 42, 889-909, https://doi.org/10.1175/JPO-D-11-092.1.

24. Hibiya, T., N. Furuichi, and R. Robertson, 2012: Assessment of fine-scale parameterizations of turbulent dissipation rates near mixing hotspots in the deep ocean. Geophys. Res. Lett., 39, L24601, https://doi.org/10.1029/2012GL054068.

25. Alford, M. H., J. A. MacKinnon, H. L. Simmons, and J. D. Nash, 2016: Near-inertial internal gravity waves in the ocean. Ann. Rev. Mar. Sci., 8, 95-123, https://doi.org/10.1146/annurev-marine-010814015746 .

26. Chang, M. H., R. C. Lien, Y. J. Yang, and T. Y. Tang, 2011: Nonlinear internal wave properties estimated with moored ADCP measurements. J. Atmos. Ocean. Technol., 28, 802-815, https://doi.org/10.1175/2010JTECHO814.1.

27. Chen, G., H. Xue, D. Wang, and Q. Xie, 2013: Observed near-inertial kinetic energy in the northwestern South China Sea.J. Geophys. Res. Oceans, 118, 4965-4977, https://doi.org/10.1002/jgrc.20371.

28. Cao, A., Z. Guo, J. Song, X. Lv, H. He, and W. Fan, 2018: Near-inertial waves and their underlying mechanisms based on the South China Sea internal wave experiment (2010-2011). J. Geophys. Res. Oceans, 123, 5026-5040, https://doi.org/10.1029/2018JC013753.

29. Deines, K. L., 1999: Backscatter estimation using broadband acoustic Doppler current profilers. IEEE Sixth Working Conference on Current Measurement, San Diego, USA, IEEE, https://doi.org/10.1109/CCM.1999.755249. 
30. Dimassa, D. E., B. A. Magnell, and J. M. Lund, 2001: Effects of temporal and vertical variability of echo amplitude on ADCP selection and performance. MTS/IEEE Oceans 2001. An Ocean Odyssey. Conference Proceedings, Honolulu, USA, IEEE, https://doi.org/10.1109/OCEANS.2001.968240.

31. Rennie, C. D., and F. Rainville, 2006: Case study of precision of GPS differential rectification strategies: influence on ADCP velocity and discharge estimates. J. Hydr. Engin., 132, https://doi.org/10.1061/(ASCE)0733-9429(2006)132:3(225).

32. Vazquez, H. J., J. Gomez-Valdes, M. Ortiz, and J. A. Dworak, 2011: Detiding shipboard ADCP data in eastern boundary current.J. Atmos. Ocean. Technol., 28, 94-103, https://doi.org/10.1175/2010JTECHO697.1.

33. Lee, I. H., and J. T. Liu, 2006: Rectification of the heading and tilting of sediment trap arrays due to strong tidal currents in a submarine canyon. Geophys. Res. Lett., 33, L08609, https://doi.org/10.1029/2005GL025183.

34. Matte, P., Y. Secretan, and J. Morin, 2014: A robust estimation method for correcting dynamic draft error in PPK GPS elevation using ADCP tilt data. J. Atmos. Ocean. Technol., 31, 729-738, https://doi.org/10.1175/JTECH-D-13-00133.1.

35. Sun, J., J. C. Zuo, Z. Lin., and Y. Yan, 2016: Role of ocean upper layer warm water in the rapid intensification of tropical cyclones: a case study of Typhoon Rammasun (1409). Acta Oceanol. Sin., 35, 63-68, https://doi.org/10.1007/s13131-015-0761-1. 